\title{
HOUSEHOLD ELECTRICITY DEMAND, REVISITED
}

\author{
Peter C. Reiss \\ Matthew W. White \\ Working Paper 8687 \\ http://www.nber.org/papers/w8687 \\ NATIONAL BUREAU OF ECONOMIC RESEARCH \\ 1050 Massachusetts Avenue \\ Cambridge, MA 02138 \\ December 2001
}

We thank Jerry Royer of the California Public Utilities Commission for valuable help in accessing and interpreting Commission records, and Brent Goldfarb for research assistance. White gratefully acknowledges the hospitality and support of the George J. Stigler Center at the University of Chicago. The views expressed herein are those of the authors and not necessarily those of the National Bureau of Economic Research.

(C) 2001 by Peter C. Reiss and Matthew W. White. All rights reserved. Short sections of text, not to exceed two paragraphs, may be quoted without explicit permission provided that full credit, including $(\mathrm{C}$ notice, is given to the source. 
Household Electricity Demand, Revisited

Peter C. Reiss and Matthew W. White

NBER Working Paper No. 8687

December 2001

JEL No. C4, L5, L9

\begin{abstract}
Recent efforts to restructure and partially deregulate electricity markets have renewed interest in understanding how consumers respond to price changes. Several interrelated problems complicate demand analyses of these markets, including nonlinear pricing, heterogeneity in households' price sensitivities, and data aggregation. This paper formulates a model of household electricity demand that addresses these difficulties. We estimate the model using data for a representative sample of California households, and summarize how electricity demand elasticities vary in that state. We then use the model to analyze the electricity consumption and expenditure effects of recent tariff structure changes in California.
\end{abstract}

Peter C. Reiss

Graduate School of Business

Stanford University

Stanford, CA 94305-5015

and NBER

preiss@stanford.edu
Matthew W. White

Graduate School of Business

Stanford University

Stanford, CA 94305-5015

and NBER

mwhite@stanford.edu 


\section{Introduction}

In regulated industries, private firms and public agencies commonly price their services using complex tariffs. The structure of these tariffs reflect a rich set of objectives, involving both efficiency concerns and provision of specific benefits to distinct consumer groups. A shortcoming of this phenomenon is that a great deal of effort is required to alter these tariffs in response to evolving demand or cost conditions. This is especially true in markets for 'essential' household services, such as electricity, water, or local phone service, where price changes can provoke considerable public concern. In these settings, it is useful to have demand models that indicate how households' consumption and expenditures would change in response to a new tariff system.

In this paper, we present a model of household electricity demand. Although the econometric literature on electricity demand is extensive, surprisingly few papers have examined how demand is affected by the structure of a firm's tariffs. This despite the fact that nonlinear tariff designs are ubiquitous in these markets, and are chosen by firms and regulatory agencies to influence consumer behavior. Moreover, studies that have considered the implications of nonlinear pricing generally do so in a 'reduced form' manner. In the absence of an underlying behavioral model, the results cannot be used to simulate how consumption would differ under an alternative tariff structure.

The model we estimate examines the influence of tariff design on consumer behavior. Our approach is based upon a microeconomic analysis of demand under nonlinear pricing, so that the estimated model can be used to evaluate consumption behavior under different tariff structures. The framework also addresses several estimation issues present in markets with nonlinear prices, including consumer self-selection along a nonlinear price schedule, tariffs tailored to customer-specific characteristics (such as price discounts to lower-income households), and heterogeneity in consumers' price sensitivities. Models that ignore these important features will tend to mis-specify price effects and yield misleading predictions of demand behavior.

We estimate the model using data for a representative probability sample of California households, obtained primarily from the Residential Energy Consumption Survey of the U.S. Department of Energy. The rich detail on appliance holdings and dwelling characteristics in these data allow us to model the considerable variation in households' electricity use and price sensitivity. Each household in the data is matched with its complete, seasonally-varying electric rate schedule for the purposes of this study. The use of disaggregated rate schedule information is a central feature of the

analysis, both to minimize specification error in estimation and to evaluate individual behavioral responses to alternative rate structures. 
The final portion of the paper examines the effects of a new tariff design in California. Following an electricity supply crisis in that state, regulatory authorities recently approved a novel, five-part tariff structure for household electricity consumption. This design was intended to induce energy conservation, raise additional revenue for utilities, and minimize expenditure changes for lower-income households. Due to its unprecedented form, however, little was known about how well the new system would achieve these objectives prior to the tariff adoption. We use the estimated demand model to illustrate the effects of these complex tariff changes.

The paper proceeds in two distinct parts. The first addresses demand models with nonlinear prices. Section 2 lays the economic groundwork for our empirical methods, and highlights why our approach differs from earlier electricity demand studies. In particular, it summarizes how consumption with a nonlinear price schedule relates to the demand specifications normally estimated in applied research. Section 3 discusses stochastic specifications and the endogenous customer sorting problem that occurs with nonlinear prices. Our treatment casts these inter-related issues in a selfselection framework, along the lines of Heckman (1979). The analysis extends Hanemann's (1984) and Hausman's (1985) techniques for modeling choice with nonlinear budget constraints.

The balance of the paper centers on the application. Section 4 describes the empirical model of household electricity demand. Building on prior work, this model explains heterogeneity in households' electricity price elasticities in terms of appliance holdings and use. In Section 5 we discuss estimation using an exact (non-linear) method of moments. This allows us to avoid certain temporal aggregation biases common to electricity demand research. Section 6 summarizes the data, and Section 7 presents

estimation results, elasticities, and an out-of-sample test of the model. In Section 8 we then illustrate how the model and methods lend themselves to analyzing prospective tariff changes, such as California's complex new tariff design.

\section{Consumer Demand with Nonlinear Prices}

Most nonlinear price schedules take the form of multi-part tariffs. In a multi-part tariff, the marginal price charged to a consumer changes in a step-wise fashion with the quantity demanded. Depending on the context, these tariffs may exhibit increasing or decreasing marginal prices. Figure 1 depicts a simple two-part increasing price schedule, $s(p)$, in which the consumer pays a low price $p^{L}$ for each unit up to the quantity $\bar{x}$, and a higher price $p^{H}$ thereafter. This type of increasing block (or "tiered") price schedule is used by most California electric utilities. In other regions, electricity tariffs are 
commonly decreasing and thereby provide volume discounts. Empirical methods for analyzing increasing and decreasing price schedules proceed along similar lines, albeit with some adjustments. For simplicity, we shall focus below on the increasing-tier case shown in Figure 1.

Economic theory offers considerable guidance on how consumers will respond to nonlinear prices. Since at least Gabor (1955), economists have realized that multi-part prices imply that the consumer faces a nonlinear (i.e., a kinked) budget constraint. The demand behavior of a utility-maximizing consumer thus depends not on the average price, nor any single marginal price, but on the entire price schedule. The difficulty that arises in empirical work is how to incorporate a complex price schedule into a demand specification in a way that is consistent with economic theory yet tractable empirically.

The standard econometric approach to this problem, which traces to Hall (1973), is to 'linearize' the budget constraint. This amounts to using the plane tangent to the consumer's nonlinear budget constraint at the optimal consumption bundle as its linear approximation. By doing so, one can express demand under nonlinear pricing in terms of the ordinary demand function of classical consumer theory, which assumes a linear budget constraint.

To be specific, let $x(p, y)$ be the ordinary demand function that indicates the consumer's desired quantity facing a constant (marginal and average) price $p$ and income $y .{ }^{1}$ Then the optimal consumption bundle $x^{*}$ for a consumer faced with an increasing nonlinear price schedule satisfies

$$
x^{*}=x\left(p^{*}, y^{*}\right)
$$

where $p^{*}$ is the slope of the approximating linear budget constraint and $y^{*}=y+\bar{x} \cdot\left(p^{*}-\right.$ $\left.p^{L}\right)$. In economic terms, $p^{*}$ is the consumer's equilibrium marginal willingness-to-pay and $y^{*}$ is the income level that would induce consumption $x^{*}$ at this (constant) price. ${ }^{2}$ With (1), the demand specification problem under nonlinear pricing can be recast in terms of the ordinary demand function familiar to applied work. Note that both $p^{*}$ and $x^{*}$ are endogenously determined, according to the three-equation system consisting of (1), the expression for $y^{*}$, and the nonlinear price schedule $s\left(p^{*}\right) .^{3}$

\footnotetext{
${ }^{1}$ To strip the analysis to its essentials, we implicitly assume a two-good setting with strictly convex preferences and that the outside good serves as a numeraire.

${ }^{2}$ Note that $p^{*}$ is the consumer's marginal willingness-to-pay, which is not necessarily the consumer's marginal price. The two will differ when demand crosses supply in the 'gap' between the two tiers in the price schedule (see Fig. 1), in which case $p^{*}$ takes a value between $p^{L}$ and $p^{H}$ but the marginal price remains $p^{L}$.

${ }^{3}$ The case with decreasing block prices is slightly more complex, because of the possibility that demand
} 
Nearly all previous studies of household electricity demand have based estimation-either implicitly or explicitly_on a single-equation analog of equation (1). Because the marginal price is simultaneously determined by a supply equation and a demand equation, standard econometric arguments imply that ordinary least squares estimation using $p^{*}$ will yield biased and inconsistent estimates of demand parameters. Recognizing as much, most previous studies have used either an exogenous proxy for the marginal price or instrumental variables procedures in estimation. While either method can alleviate the endogeneity problem, both introduce biases of their own: the former due to mis-specification of the appropriate marginal price, and the latter because of the difficulty in finding good instruments (that do not a priori belong in the demand equation) in this setting. As neither of these problems are readily dismissed, it becomes worthwhile to consider more sophisticated estimation methods.

An alternative formulation of this problem lends itself to econometric procedures that avoid these difficulties. The basic idea is to use the 'supply equals demand' representation in Figure 1 to determine consumption. This amounts to solving the threeequation system described above for $x^{*}$ as a function of the individual terms in the price schedule. By reference to Figure 1, we can determine consumption by evaluating demand at each marginal price to obtain

$$
x^{*}= \begin{cases}x\left(p^{L}, y\right) & \text { if } x\left(p^{L}, y\right)<\bar{x} \\ x\left(p^{H}, y^{H}\right) & \text { if } x\left(p^{H}, y^{H}\right)>\bar{x} \\ \bar{x} & \text { if otherwise, }\end{cases}
$$

where $y^{H}=y+\bar{x} \cdot\left(p^{H}-p^{L}\right)$. Equation (2) indicates that consumption is given by demand at the low price when the first tier is on the margin, by demand at the high price plus an income effect when the second tier is on the margin, and by the quantity $\bar{x}$ when demand crosses supply in the 'gap' between the two tiers of the price schedule. The term $\bar{x} \cdot\left(p^{H}-p^{L}\right)$ that is added to income in the second case is the rate structure discount: it is the difference between the expenditure necessary to purchase the higher quantities $x^{*}>\bar{x}$ under non-linear pricing, and that necessary to purchase $x^{*}$ at a constant price of $p^{H}$. In essence, when $x^{*}>\bar{x}$ the lower price for inframarginal quantities produces an income effect. ${ }^{4}$

may have multiple crossings of the price (supply) schedule. In that event these three equations have multiple solutions, and a fourth equation (involving the indirect utility function) is needed to determine consumption. This is straightforward if the econometric demand specification admits a known indirect utility function; see, e.g., Hausman (1985).

${ }^{4}$ Taylor (1975) contains an early discussion of this issue. Technically speaking, the first two cases in equation (2) are mutually exclusive only if certain restrictions on preferences hold. For a normal good (one whose consumption rises with income), these amount to assuming that the income effect is not 'too 
In principle, one could base an empirical model of demand under nonlinear pricing on either (1) or (2). In practice, (2) offers some distinct advantages. The first is that (2) expresses demand in terms of the exogenous price schedule facing the consumer, rather than the endogenously-chosen marginal price. By 'solving out' the marginal price, the simultaneity problems arising in econometric analyses using (1) can therefore be avoided. No instrumental variables nor price schedule approximations are needed.

Second, (2) shows precisely how the individual terms of a nonlinear price schedule enter the demand decision. If one proceeds from an empirical specification of the ordinary demand function that is consistent with (or perhaps derived from) some primitive utility specification, then (2) indicates how a nonlinear price schedule should be explicitly incorporated to maintain internal consistency. The discrete form in (2) is an inherent consequence of optimizing behavior when consumers face multi-part tariffs.

In this section, we have indicated how the ordinary demand function of classical consumer theory relates to consumption decisions when consumers face nonlinear prices. This is useful for two purposes-fitting demand models to existing consumption data, and making predictions for new price schedules of a similar form. To be more specific about how to do these tasks, it is necessary to consider stochastic specifications for demand.

\section{Stochastic Specifications and Expected Consumption}

In empirical work, consumer demand functions typically take the form

$$
x(p, y, z, \varepsilon)
$$

where $z$ represents observed consumer characteristics, and $\varepsilon$ is a stochastic term. This type of demand function implicitly assumes the consumer can purchase any quantity desired at a constant price $p$. When this assumption is valid, the economic interpretation of the stochastic term is usually of little consequence for estimation.

When consumers face nonlinear prices, the interpretation given to the stochastic term has economic ramifications. In a structural model, the usual interpretation of the stochastic term is that it reflects (in whole or in part) unobservable heterogeneity in consumers' preferences. That is, the individual consumer is assumed to know his or her particular value of $\varepsilon$, but the firm and the econometrician do not and so treat $\varepsilon$

large'; or, more specifically, that the income effect of the rate structure discount does not dominate the substitution effect of the higher marginal price. If this fails, the conditioning event inequalities in (2) are more complex. 
as random. In this setting, the probability distribution of $\varepsilon$ conveys information about how willingness-to-pay varies in the population.

This poses some interesting complications for estimating consumer demand functions and calculating expected demand. With a multi-part tariff schedule, such as the one illustrated in Figure 1, consumers will sort themselves between tariff segments according to willingness-to-pay. The marginal price is therefore self-selected in a way that depends upon the observed as well as the unobserved characteristics of the consumer. This selection induces correlation between the marginal price and the stochastic term. For example, suppose that $\varepsilon$ enters the demand function additively, and the consumer faces an increasing two-tier price schedule. Then a consumer with an unusually low value of $\varepsilon$-due to, say, idiosyncratic preferences for energy conservation or extended travel away from home-will tend to have low total consumption and consequently a lower marginal price. Ceteris paribus, consumers on the lower marginal price will tend to be drawn from the lower end of the distribution of $\varepsilon$, and consumers on the higher marginal price will tend to be drawn from the upper end of the distribution of $\varepsilon$. This sorting makes calculating expected demand difficult, because one must account for the consumer's willingness to switch tariff segments (thus marginal prices) when integrating out the unobservables.

Handling these complications requires explicitly modeling the selection behavior of the consumer. We will do so assuming the consumer's ordinary demand function (demand at a constant price $p$ ) takes the econometric form

$$
x(p, y, z ; \beta)+\varepsilon
$$

where $\beta$ is a set of parameters to be estimated. The additive separability of $\varepsilon$ is not strictly necessary for what follows, but will simplify the analysis and make certain relations more transparent.

Consider first the consumption decision from the perspective of the consumer, who knows his or her value of $\varepsilon$. From the analysis in Section 2, we can represent this choice in a form analogous to equation (2). Specifically, if a consumer with the ordinary demand function in (3) encounters a price schedule of the type in Figure 1, then her optimal consumption level is

$$
x^{*}= \begin{cases}x\left(p^{L}, y, z ; \beta\right)+\varepsilon & \text { if } \varepsilon<c_{1} \\ \bar{x} & \text { if } c_{1}<\varepsilon<c_{2} \\ x\left(p^{H}, y^{H}, z ; \beta\right)+\varepsilon & \text { if } \varepsilon>c_{2}\end{cases}
$$

where $c_{1}=\bar{x}-x\left(p^{L}, y, z ; \beta\right)$ and $c_{2}=\bar{x}-x\left(p^{H}, y^{H}, z ; \beta\right)$. The lower and upper cutoff 
values $c_{1}$ and $c_{2}$ satisfy $c_{1}<c_{2}$ for any downward-sloping demand function, provided that income effects are not too large. ${ }^{5}$ They partition the range of $\varepsilon$ into three regions: if $\varepsilon<c_{1}$, then consumption occurs on the low-price tier, if $\varepsilon>c_{2}$ then consumption occurs on the high-price tier, and if $c_{1}<\varepsilon<c_{2}$ then demand crosses supply in the 'gap' between the two tiers of the price schedule.

From an econometric perspective, equation (4) is a censored regression model in which the censoring occurs in the interior of the distribution of outcomes rather than the tails. Such models are generally estimated by maximum likelihood methods, using the discrete structure in (4) to derive the change-of-variables from an (assumed) marginal distribution of $\varepsilon$ to the distribution of $x^{*}$. Burtless and Hausman (1978) develop a maximum likelihood implementation for a general censoring model with this structure. Their method, later extended by Hausman (1985) and others, has been widely applied for modeling labor supply decisions subject to nonlinear income taxation. ${ }^{6}$

In the present analysis, we are interested in both estimating a model of demand behavior and calculating expected consumption under observed and alternative tariff schedules. We therefore eschew maximum likelihood in favor of an exact momentbased estimation approach. This has the desirable feature that the analytic machinery needed to perform expected demand calculations (for current and alternative tariff schedules) is readily available from the model's estimating conditions. ${ }^{7}$

To obtain an expression for expected consumption, we can integrate (4) piecewise. Let $w$ represent the set of observable characteristics affecting the household's consumption decision: $w=\left\{p^{L}, p^{H}, \bar{x}, y, z\right\}$. To simplify notation, we will write $x^{H}(\beta)$ for $x\left(p^{H}, y^{H}, z ; \beta\right)$ and $x^{L}(\beta)$ for $x\left(p^{L}, y, z ; \beta\right)$. The expected value of $x^{*}$ given $w$ is then

$$
\begin{aligned}
E\left(x^{*} \mid w\right)=\left[x^{L}(\beta)+E\left(\varepsilon \mid \varepsilon<c_{1}(\beta), w\right)\right] \cdot P\left(\varepsilon<c_{1}(\beta)\right) & \\
+ & \bar{x} \cdot P\left(c_{1}(\beta)<\varepsilon<c_{2}(\beta)\right) \\
& +\left[x^{H}(\beta)+E\left(\varepsilon \mid \varepsilon>c_{2}(\beta), w\right)\right] \cdot P\left(\varepsilon>c_{2}(\beta)\right)
\end{aligned}
$$

where $P$ is the (conditional) probability distribution of $\varepsilon$, given $w$. This is a simple probability-weighted average of expected demand within each segment of the price schedule. To apply (5) to data, we will assume a parametric specification for the distribution of the unobservables. Specifically, if $P$ is the normal distribution with mean

\footnotetext{
${ }^{5} C f$. ftn. 4 .

${ }^{6}$ See Moffitt (1986) for a survey.

${ }^{7}$ There are also computational reasons to prefer this approach to maximum likelihood, which we address in Section 5.
} 
zero and variance $\sigma$, then expected consumption becomes

$$
E\left(x^{*} \mid w\right)=\left[x^{L}(\beta)-\sigma \lambda_{1}\right] \Phi_{1}+\bar{x} \cdot\left(\Phi_{2}-\Phi_{1}\right)+\left[x^{H}(\beta)+\sigma \lambda_{2}\right]\left(1-\Phi_{2}\right)
$$

where $\lambda_{1}=\phi_{1} / \Phi_{1}$ and $\lambda_{2}=\phi_{2} /\left(1-\Phi_{2}\right)$ are the inverse Mills ratios, $\phi_{1}$ and $\phi_{2}$ are the standard normal density evaluated at $c_{1}(\beta) / \sigma$ and $c_{2}(\beta) / \sigma$, and $\Phi_{1}$ and $\Phi_{2}$ the standard normal distribution function at $c_{1}(\beta) / \sigma$ and $c_{2}(\beta) / \sigma$.

Several points are worth noting here. In statistical terms, equation (5) is integrating demand over the joint probability distribution of the consumer's marginal price and the unobservables. It recognizes the fact that the consumer's marginal price is related to $\varepsilon$, and changes-in a discrete, endogenous way-as $\varepsilon$ varies. What makes this integration tractable is that price schedules are discrete, so that the marginal price and $\varepsilon$ are conditionally independent within each 'step' of the price schedule.

Second, there is a close parallel here to the sample-selection models in the econometric literature. The terms in square brackets in (6) are essentially 'Heckit'-style conditional expectation functions. They correct for the fact that, given $w$, consumers that sort onto the lower marginal price are different in their unobservable characteristics than those who choose the higher-tier price. The parallel to sample-selectivity problems arise because, in both that and the present analysis, consumers are sorting along a budget constraint. In traditional models of labor supply decisions (for example, Heckman (1974)), consumers with different reservation wages choose whether or not to participate in a labor market, effectively sorting between interior and boundary solutions on the labor-leisure budget set. In the present analysis, consumers are simply sorting between different segments of a nonlinear (i.e., kinked) budget constraint. The present situation generates greater information about the distribution of consumer preferences, however, because consumers can equate price to marginal willingness-topay at (two) different price levels. This makes (6) a more complex expression than the expectation functions employed in traditional selection models. ${ }^{8}$

In the empirical analysis of demand behavior, the expected consumption equation in (6) serves two roles. It can be used to estimate a model of demand when consumers face nonlinear tariffs of the form in Figure 1; and, given the estimated demand model,

\footnotetext{
${ }^{8}$ At the risk of confusing matters, there is one other difference between the present analysis and traditional models of labor market supply. The analysis here is more complicated because the supply and demand system is "nonrecursive." That is, in traditional labor supply models, the individual's labor supply function depends on the market wage, but the market wage is constant irrespective of the labor hours supplied. The slope of the budget constraint is therefore exogenous. In the present analysis, the quantity demanded depends on the marginal price (through substitution behavior) and the marginal price depends on the quantity consumed (through the price schedule). This leads to simultaneity problems (as discussed in Section 2) in addition to the self-selection behavior above.
} 
it can be used to calculate how expected consumption would differ under an alternative tariff of the same structure. Of course, this framework is easily generalized to more complex tariff structures, which might include fixed charges or additional tariff segments. We illustrate the latter in Section 8.

\section{Household Electricity Demand}

To obtain an estimable model, we now consider in detail the specification of a household electricity demand function $x(p, y, z ; \beta)$.

Like many household services, electricity is not consumed directly by individuals. Rather, a demand for electricity is derived from the flow of services provided by a household's durable energy-using appliances. This characteristic of electricity use implies a useful distinction between short-run and long-run demand elasticities. The 'short-run' refers to demand behavior taking a household's existing appliance stock as given. For example, in response to an increase in the price of electricity, a household might tolerate a warmer air conditioner setting or reduce the number of hours a pool filter operates. In contrast, long-run elasticities are meant to incorporate both changes in utilization behavior and any adjustments to the stock of appliances owned by the household.

This distinction is important for modeling demand behavior. The long-run effects of electricity price changes are an equilibrium outcome of households' appliance replacement decisions (on the demand side) and appliance manufacturers' choices of technological characteristics and prices for new appliances (on the supply side). Unfortunately, our present (cross-sectional survey) data does not contain the longitudinal information necessary to estimate how these replacement decisions are prompted by changing energy prices. Thus, we focus on analyzing short-run demand elasticities, and leave appliance replacement decisions for subsequent research. Our results therefore inform changes in demand due to changes in appliance utilization behavior, rather than through equilibrium appliance stock adjustments. ${ }^{9}$

This approach to modeling electricity demand amounts to conditioning econometric analysis on households' existing appliance stocks. In doing so, an important question becomes how best to incorporate information on appliance holdings into demand specifications. Households vary markedly in the set of appliances they own, so it is natural

\footnotetext{
${ }^{9}$ The element of technological change in appliance manufacturers' choices makes estimating the longrun effects of electricity price changes particularly complex. One effort to do so is the EPRI Residential End-Use Energy Planning System (REEPS) micro-simulation models; see Goett and McFadden (1985). These models build on Dubin and McFadden's (1984) model of contemporaneous appliance choice and utilization decisions.
} 
to expect the factors influencing electricity demand in one household will differ from those in the next. For example, an elderly household that uses central air conditioning much of the summer might be willing to alter its thermostat setting in response to a small change in the price of electricity, which can yield a large change in its electricity consumption. In contrast, a single-person household that uses electricity to operate only a refrigerator and a few lights might exhibit little or no demand response even to large price changes. This suggests that both a household's electricity consumption and its price sensitivity may depend delicately on the specific types of appliances it holds. ${ }^{10}$

A useful way of modeling this heterogeneity is to specify electricity demand functions at the level of the individual appliance. This allows different factors to affect electricity demand for different appliances, and thus for different households. This approach to modeling electricity demand is feasible with household-level data, provided both appliance ownership and energy consumption are observed. In our data, however, electricity consumption is not recorded at the level of the individual appliance; rather, we observe only total household electricity consumption (at the level of the household's electric meter). Consequently, we treat the electricity used by each of a household's individual appliances as a latent, or unobserved, outcome. We then aggregate these appliance-level demand specifications to obtain a model of household electricity demand. ${ }^{11}$

Specifically, we treat total household demand as the sum of electricity used by $K$ distinct appliance categories. These categories include space heating, water heating, air conditioning, refrigeration, pools, and a residual category of other electrical appliances. If a household owns an appliance of type $k=1,2, \ldots, K$, we assume that electricity consumption (per billing period) for the category, $x_{k}$, takes the linear form

$$
x_{k}=\alpha_{k} p+\gamma_{k} y+z_{k}^{\prime} \delta_{k}+\varepsilon_{k}
$$

where $p$ is the price of electricity, $y$ household income, $z_{k}$ a vector of observable household characteristics, and $\varepsilon_{k}$ unobservable household characteristics. The unknown demand parameters $\alpha_{k}, \gamma_{k}$, and $\delta_{k}$ are assumed constant across households and are to be estimated. Depending on the appliance, the category-specific vector $z_{k}$ may include household demographic information, dwelling structure characteristics, appliance at-

\footnotetext{
${ }^{10} \mathrm{~A}$ separate issue not examined here is that the choice of major appliances in a residence is ultimately endogenous, and may be statistically endogenous to a model of utilization behavior. Dubin and McFadden (1984) present some evidence on this issue in the choice of gas versus electric home heating systems.

${ }^{11}$ This latent-variables approach to modeling electricity consumption is implicit in Fisher and Kaysen's (1962) pioneering work on aggregate electricity demand. Later studies using related approaches include Parti and Parti (1980), Barnes, Gillingham, and Hagemann (1981), and Dubin (1985).
} 
tributes, and (contemporaneous billing-period) weather data. We interpret equation (7) as household demand when it faces a constant (marginal and average) price, $p$.

As noted above, we do not observe electricity consumption at the level of the individual appliance; rather, we observe total household electricity consumption. Total and appliance-level electricity demand are related by

$$
x=\sum_{k=1}^{K} d_{k} x_{k}
$$

where $x$ is total household electricity consumption and

$$
d_{k}=\left\{\begin{array}{l}
1 \text { if household owns appliance type } k \\
0 \text { if otherwise }
\end{array}\right.
$$

With household appliance ownership information, we can insert (7) into (8) to obtain an estimable equation for household electricity demand,

$$
x=\sum_{k} d_{k} \alpha_{k} p+\sum_{k} d_{k} \gamma_{k} y+\sum_{k} d_{k} z_{k}^{\prime} \delta_{k}+\sum_{k} d_{k} \varepsilon_{k}
$$

which we will collapse to

$$
x=\alpha p+\gamma y+z^{\prime} \delta+\varepsilon
$$

by setting $\alpha=\sum_{k} d_{k} \alpha_{k}, \gamma=\sum_{k} d_{k} \gamma_{k}$, and so on. Although equation (9) looks like a conventional linear demand function, the price, income, and other slope coefficients depend upon the household's appliance portfolio. Notice that we are not estimating $\alpha$ directly, but rather the parameters $\alpha_{1}, \alpha_{2}, \ldots, \alpha_{K}$ that characterize the pricesensitivity of each appliance category (and similarly for $\gamma, \delta$ ). Thus, this specification allows households with numerous electricity-intensive appliances, such as air conditioners, swimming pools, or electric space heating systems, to exhibit different price and income elasticities than households without such appliances.

In interpreting equation (9), it is important to note that it corresponds conceptually to the conventional demand function $x(p, y)$ of classical consumer theory, as discussed earlier. That is, it specifies the amount of electricity the household would consume if it faced income level $y$ and a constant price $p$ for electricity. This differs from the situation in our data, where households face a nonlinear price schedule with marginal prices $p^{L}$ and $p^{H}$. In that case, the optimal consumption level is given by evaluating demand using the schedule derived in equation (4). The expected value of demand is similarly determined, by appropriately inserting the demand specification (9) into the 
expected consumption equation (6).

\section{Variances}

An important aspect of this model of electricity demand is that the household-level demand error, $\varepsilon$, is heteroscedastic. This occurs because the stochastic term in the household-level demand specification is the sum of the stochastic terms associated with the $K$ appliance utilization equations (7). The variance of the household-level stochastic term therefore depends upon which appliances are held by the individual household.

Specifically, from the expressions leading to (9), the variance of the household-level stochastic term is a function of the appliances owned:

$$
\begin{aligned}
\operatorname{var}(\varepsilon) & =\sum_{j=1}^{K} \sum_{k=1}^{K} d_{j} d_{k} \operatorname{cov}\left(\varepsilon_{j}, \varepsilon_{k}\right) \\
& \equiv \sigma\left(d_{1}, d_{2}, \ldots, d_{K}\right)^{2}
\end{aligned}
$$

Thus, even if the stochastic term in a particular appliance utilization equation is assumed to have constant variance across households, the household-level stochastic term will not have constant variance. We tend to think of the appliance-level stochastic terms as reflecting households' idiosyncratic tastes for utilizing appliances. A variety of behavioral considerations then suggest that the covariance terms entering (10) will tend to be positive, so that the variance of the household-level stochastic term will increase with the number of appliances owned.

From an econometric perspective, equation (10) is a simple model of group-wise heteroscedasticity in which the 'group' is a specific portfolio of household appliances. Normally, this would not be a major concern for estimating the parameters of a linear demand specification such as (9). When consumers face nonlinear prices, however, the variance of the household-level stochastic term affects the likelihood that a consumer will fall on one tariff segment or another. This can be seen immediately from equation (6), where (the root of) the variance term, $\sigma$, enters the conditional expectation function and the tariff segment probabilities. The variance of unobserved tastes thus affects expected consumption calculations, and consistent estimation of the demand parameters. 


\section{Estimation}

In theory, one can estimate the model given by (4) and (9) using several different methods. In practice, however, both data limitations and computational considerations limit the appeal of likelihood-based estimators. Before turning to the specific estimation technique we employ, we first describe two issues that affect estimation procedures. These relate to aggregation of the household's consumption decisions over time, and a partial identification problem of the model with normally-distributed unobservables.

\subsection{Aggregation over Time}

Because electricity is sold using a nonlinear price schedule, there is an important temporal aspect to electricity demand. In practice, the multi-part tariffs discussed in Sections 2 and 3 apply to households' electricity consumption on a monthly basis. In contrast, the data available to us provide only annual household electricity consumption information. This temporal mismatch creates a potential source of aggregation bias, since the household may choose to consume at different prices during different times of the year.

There are both supply (price schedule) and demand-based reasons to expect the household's marginal price will vary over the course of the year. First, many household electricity uses are seasonal and weather-sensitive (e.g., air conditioning and space heating). These appliances are quite energy-intensive, and can easily push a household onto a higher segment of its tariff schedule during the months these appliances are used. Second, even if a household's electricity demand did not change from month to month, electricity tariff schedules do-both because of seasonal tariff changes (rates differ between summer and winter) and mid-year regulatory adjustments. No single price schedule applies to all of a household's annual consumption activity.

The problems this poses for estimation are considerable. When only annual consumption data are available, the household's monthly consumption and actual marginal prices are unobserved. Consequently, there is no way to know what sequence of monthly marginal prices generated a household's aggregate consumption outcome. In a completely linear demand model, this is of no special concern because annual demand depends on only the average annual price. When consumers face nonlinear prices, however, no such simplifications are possible. The aggregation must be modeled explicitly to avoid mis-specifying the effect of price on demand.

A second, and more subtle, issue is that the same applies to the effect of weather and other time-varying covariates. Precisely because consumers face nonlinear tariffs,

the effects of other time-varying covariates will tend to be confounded in aggregate 
data. For example, a decrease in demand over a period of several cooler-than-usual summer months could be due solely to the effect of the weather, or due to an increase in seasonal tariffs during the summer, or due to a composition of these two simultaneous effects. With only annual data, it becomes difficult to disentangle and separately identify the direct effect of monthly marginal price changes. Yet this is precisely what is required if we are to understand the effects of changing tariff schedules on consumption behavior.

Addressing this problem constructively requires some information about the way prices and other time-varying covariates change during the year. For the present analysis, we obtained location-specific monthly weather information and complete seasonally-varying electric rate schedules for each household in the data. This allows us to model the household's monthly consumption decisions explicitly, treating the unobserved monthly consumption outcomes as latent variables. We then aggregate these latent variables to obtain a demand model that matches the annual consumption outcomes available.

More precisely, let $w_{t}$ denote the set of observable variables affecting the household's consumption decision in month $t$, including the applicable monthly price schedule and that month's weather conditions. Let $x_{t}^{*}$ denote the household's electricity consumption in month $t$, and $x^{a}=\sum_{t=1}^{12} x_{t}^{*}$ the household's annual electricity consumption. The value of $x_{t}^{*}$ for month $t$ is determined by (4), using the right-hand side covariates for that month.

To estimate the model using a method of moments, we require an expression for the expected value of annual demand, $E\left[x^{a} \mid w_{1}, w_{2}, \ldots, w_{12}\right]$. Exploiting linearity of expectations, we will assume

$$
E\left[x^{a} \mid w_{1}, w_{2}, \ldots, w_{12}\right]=\sum_{t=1}^{12} E\left[x_{t}^{*} \mid w_{t}\right]
$$

where $E\left[x_{t}^{*} \mid w_{t}\right]$ is as defined in (6). That is, we evaluate the (conditional) expectation of annual demand by evaluating the monthly expected consumption equation twelve times, using the appropriate covariates for each month. There is no simple form for otherwise calculating the expected value of annual demand. ${ }^{12}$

\footnotetext{
${ }^{12}$ In theory, one could estimate this model more efficiently using maximum likelihood, or possibly Heckman's (1979) two-stage technique for censored regression models. Unfortunately, maximum-likelihood methods quickly becomes computationally intractable when consumption decisions made at varying prices are aggregated. To illustrate, the likelihood function for one monthly consumption outcome in this model is a mixed continuous/discrete function, with three discrete segments (this follows from (4); see Hausman (1985) for more details). In contrast, the likelihood function for the sum of twelve month's consumption outcomes involves $3^{12}$, or approximately 531 thousand distinct segments. While there is
} 
Equation (11) makes an assumption regarding the additive separability of the conditioning sets. This entails some restrictions on household substitution behavior over time. If we assume that households consume electricity out of permanent rather than contemporaneous (i.e., monthly) income, the only time-varying elements in $w_{t}$ are the weather-related covariates (monthly heating and cooling degree-days) and the price schedules (being seasonal). Equation (11) makes the implicit assumption that, conditional on a household's existing appliance stock, knowledge of the electricity price schedules and weather patterns for past and future months this year has no effect on the current month's consumption. While untestable directly, this is a tenable assumption given that electricity is a non-storable commodity: Households cannot stockpile it in anticipation of higher demand or prices in other months.

\subsection{Estimation Method}

The foregoing discussion suggests a straightforward, albeit nonlinear, least-squares procedure for estimation. This is to choose as estimates the values of the unknown parameters that minimize the difference between the observed and expected annual consumption outcomes. Unfortunately, with a finite sample of data the variance parameters in (10) tend to be poorly identified on the basis of the conditional expectation of demand alone. This is because, for some realizations of the data, the conditional expectation function (6) may be nearly flat with respect to $\sigma$ in a broad region containing the true value of this parameter. In essence the first moments of the sample may contain too little information to estimate the variance of the stochastic term accurately, absent an impractically large sample.

To resolve this problem, it is necessary to incorporate information on the higher moments of the model into estimation. We employ a generalized method of moments (GMM) procedure based on the first and second moments of annual consumption, using the following technique. Let $h_{r}(\mathcal{W}, \theta)=E\left[\left(x^{a}\right)^{r} \mid \mathcal{W}\right]$ denote the $r$-th conditional moment of annual consumption. Here $\theta$ denotes the set of unknown parameters to be estimated, and $\mathcal{W}=\left\{w_{1}, w_{2}, \ldots, w_{12}\right\}$ is the set of all observable variables influencing the household's annual consumption. We base inference on a pair of first- and second-moment differences between observed and expected annual consumption:

$$
\begin{aligned}
& u_{1}=x^{a}-h_{1}(\mathcal{W}, \theta) \\
& u_{2}=\left(x^{a}\right)^{2}-h_{2}(\mathcal{W}, \theta)-2 h_{1}(\mathcal{W}, \theta)\left(x^{a}-h_{1}(\mathcal{W}, \theta)\right) .
\end{aligned}
$$

some redundancy involved, the task of evaluating such a likelihood function (for use in either direct or simulated likelihood methods) appears quite burdensome. 
By construction, both $u_{1}$ and $u_{2}$ have conditional mean zero given $\mathcal{W}$. The cross-product term in the second equation, $-2 h_{1}\left(x^{a}-h_{1}\right)$, is added to improve the sampling performance of the estimator: if $\left(x^{a}\right)^{2}>h_{2}$ then the cross-product term tends to be negative, and conversely if $\left(x^{a}\right)^{2}<h_{2}$, which reduces the sampling variance of $u_{2}$. The second equation amounts to basing inference on the centered, rather than uncentered, second moment of annual consumption.

The functional form of $h_{1}(\mathcal{W}, \theta)$ is given by (11) and (6). The functional form of $h_{2}(\mathcal{W}, \theta)$ is derived similarly, and involves the second moment of the truncated normal distribution. In doing so, an additional complication arises due to the temporal aggregation of monthly consumption outcomes. While computing $h_{1}$ involves only the mean and variance of the stochastic term $\varepsilon$ in the underlying demand specification, evaluating $h_{2}$ requires an assumption about the correlation of $\varepsilon$ over time. We assume that the value of $\varepsilon$ in the household's demand specification (9) is independent from month to month. This simplification is motivated by computational concerns, as an autocorrelation structure for the unobservables is likely to be difficult to identify with annual consumption data.

From the conditional moment differences $u_{1}$ and $u_{2}$, we construct orthogonality conditions for GMM in a standard manner. By classical arguments, optimal instruments in this setting involve (covariance-weighted) derivatives of the conditional moments $h_{1}$ and $h_{2}$. We use the gradients of the first and second conditional moments, setting

$$
z_{1}(\mathcal{W}, \theta)^{\prime}=\nabla_{\beta} h_{1}(\mathcal{W}, \theta)
$$

and

$$
z_{2}(\mathcal{W}, \theta)^{\prime}=\left[\begin{array}{l}
\nabla_{\beta} h_{2}(\mathcal{W}, \theta) \\
\nabla_{\xi} h_{2}(\mathcal{W}, \theta)
\end{array}\right]
$$

Here $\beta$ denotes the demand parameters from (9) and $\xi$ a vector of the variance terms from (10), with $\theta=(\beta, \xi)$. The unconditional orthogonality conditions are then $E\left[z_{r}^{\prime} u_{r}\right]=$ $0, r=1,2$. This instrument set yields $m=2 \cdot \operatorname{dim}(\beta)+\operatorname{dim}(\xi)$ moment equations for estimation and $\operatorname{dim}(\beta)$ over-identifying restrictions. ${ }^{13}$ Note that the gradient of $h_{1}$ with respect to the variance parameters is excluded from the instruments, for the sample analog contains no useful information (it is essentially singular if incorporated into estimation-this is the reason the variance parameters are poorly identified by nonlinear least squares estimation using the first moments alone).

\footnotetext{
${ }^{13}$ It may be verified by direct analysis that these instruments preserve a unique solution for $\theta$ to the $m$ equations $E\left[z_{r}^{\prime} u_{r}\right]=0, r=1,2$, provided that the household variance function $\sigma\left(d_{1}, d_{2}, \ldots, d_{K}\right)^{2}$ is bounded away from zero.
} 
Our estimator minimizes the usual GMM distance metric $\|A u(\theta)\|^{2}$, where $A$ is an $(m \times 2 n)$ weighting matrix held fixed during minimization, and

$$
u(\theta)=\left[\begin{array}{l}
u_{1}(\theta) \\
u_{2}(\theta)
\end{array}\right]
$$

is the $2 n$-vector of 'stacked' first and second conditional moment differences for all $n$ households. The matrix $A=\tilde{R} \tilde{Z}^{\prime} D$, where $D$ is a diagonal matrix containing the appropriate survey sampling weight for each observation, $\tilde{Z}$ is the $(2 n \times m)$ matrix of instruments evaluated at an initial consistent estimate of $\theta$, and $\tilde{R}$ is the (upper) Cholesky factor of an approximation to the inverse moment covariance matrix. Specifically, $\tilde{R}^{\prime} \tilde{R}=\left[D \tilde{Z}^{\prime} \tilde{\Omega} \tilde{Z} D\right]^{-1}$, where $\tilde{\Omega}$ is an estimate of the covariance matrix $\Omega=E\left[u(\theta) u(\theta)^{\prime} \mid \mathcal{W}\right]$. Under the model, the matrix $\Omega$ is known up to the parameters $\theta$ and has a simple tri-diagonal form. In particular, the non-zero elements are the second through fourth conditional moments of annual consumption. We calculate these higher moments analytically (as a function of the parameters), and then evaluate $\Omega$ at an initial consistent estimate of $\theta$ to obtain $\tilde{\Omega}$.

To obtain final parameter estimates, we iterated minimization of the GMM distance metric five times using successive updates of the matrix $A .{ }^{14}$ Full optimization required approximately six minutes on a $450 \mathrm{MHz}$ computer, with $m=270$ moment equations and 212 estimated parameters. Numerical optimization was performed using a modified Gauss-Newton algorithm based on trust-region subspace minimization, and implemented in Matlab. ${ }^{15}$

\section{Data and Empirical Specifications}

We estimate the model using data from the Residential Energy Consumption Survey (RECS). The RECS is conducted every three to four years by the U.S. Department of Energy to collect information on household appliances and energy use. The survey is a nationally representative probability sample of households, with representative subsamples for several large states. We use the California subsamples of the 1993 and 1997 survey waves, which are the most recent available. Together they provide information on 1,307 California households. ${ }^{16}$

The survey is conducted by in-home interview. Interviewers inventory the house-

\footnotetext{
${ }^{14}$ The first-round estimate of $\theta$ provides the initial consistent estimate.

${ }^{15}$ For discussion of recent trust-region optimization methods, see Nocedal and Wright (1999).

${ }^{16}$ The RECS sample design mirrors that of the U.S. Consumer Population Survey. There is no longitudinal component to the 1993 and 1997 RECS.
} 
hold's appliances, assess physical characteristics of the residence, and collect demographic information. The survey also includes weather data (heating and cooling degree-days) for each household, which are obtained from the nearest National Weather Service (NWS) station during the survey year. To minimize measurement error, each household's metered energy consumption is collected directly from the household's energy supplier. The household survey response rate is 81 percent, and the subsequent supplier survey response rate is over 90 percent. ${ }^{17}$

The appliance information, representativeness, and quality of the consumption data make the RECS particularly valuable for analyzing household electricity demand. There are, however, two noteworthy shortcomings of the RECS data. The first is that the RECS public-use files only provide annual household electricity consumption and expenditures. This poses problems for relating consumption to monthly prices, and motivated our efforts to address temporal aggregation in Section 5.1.

The second shortcoming pertains to the limited electricity tariff information available in the survey. Inadequate pricing data are a first-order problem for many previous studies of electricity demand and for other researchers using the RECS. Our considerable efforts to rectify this problem merit a brief digression here.

\subsection{Prices}

During the sample period most California households faced an increasing two-tier electricity price schedule each month, such as the one depicted in Figure 1. These schedules vary by service provider, climate zone, household heating system, household income, and season. For example, the state's largest utility, Pacific Gas and Electric (PG\&E), offers residential service rate schedules that differ in summer and winter months, by whether the household has permanently-installed electric heat or not, by whether the household is designated as low-income or not, and in which of nine climate zones the household resides. Thus, PG\&E had $72(=2 \times 2 \times 2 \times 9)$ standard residential rate schedules in effect during 1993, and again (with different tariffs) in 1997. A similarly complex structure applies to other major utilities. ${ }^{18}$

The RECS data provide two summary price measures for each household. The first is the household's annual average electricity price, in cents per kilowatt-hour. The second is the local electric utility's annual average revenue per KWh sold to all its residential customers. Either of these price measures unfortunately presents problems

\footnotetext{
${ }^{17}$ Detailed information about the RECS data and survey design is available in EIA $(1994,1996)$.

${ }^{18}$ There are also special rate schedules for households with medical equipment, utility employees, and families living in trailer parks. There are sufficiently few households on these rates that we have ignored these schedules on probabilistic grounds.
} 
for modeling electricity demand at a disaggregate (household) level. Since electricity rates increase with monthly consumption, the first of these two price measures is endogenous (it rises with consumption) and bears a complex relation to the household's monthly use. The second, utility-level average price, while putatively exogenous, will typically mis-measure the marginal price faced by a household. Thus, either summary price measure could be expected to provide poor information regarding the actual (marginal) price facing the household each month. ${ }^{19}$

To address these shortcomings, we developed a procedure for matching each observation in the RECS with the complete rate schedule facing the household. The data this requires that are not provided in the RECS are each household's utility and its utility-designated climate zone. To determine these, we exploit three types of information in the RECS about the household: the local utility's average electricity price, the availability and price of natural gas, and the weather information. The weather data provide considerable information regarding where in California's diverse climate zones each household is located. The electricity and natural gas price data help pinpoint the household's service provider. ${ }^{20}$

We use a discriminant procedure to match each RECS household to its utility service provider and climate zone. First, we used maps of utility service areas to assign each of the approximately 240 National Weather Service (NWS) stations in California to one (or two adjacent) utility service territories. We also collected the local average electricity and gas prices for each service territory in the state. These weather and price data are the same primary data series accessed by the RECS designers and included with each household in the survey. ${ }^{21}$ Our algorithm then determines each household's utility and climate zone based on how well the household's information in the RECS matches the known average price and weather information for each utility and NWS station in California.

\footnotetext{
${ }^{19}$ By standard econometric arguments, we expect estimated price elasticities based on such measures to be biased downward in this setting. There is an additional problem with the RECS' utility-level price measure, in that the firm that conducts the survey introduces a small amount of measurement error into this price for confidentiality reasons.

${ }^{20}$ An example may help. Palo Alto, a city on the San Francisco Bay, has its own municipal utility that charged between 5 and 6 cents per KWh during our sample period. Palo Alto is surrounded by PG\&E's service territory, which includes neighboring cities such as Mountain View that have similar weather. What distinguishes a household served by the City of Palo Alto from one served by PG\&E in Mountain View in the data is that Mountain View residents' electricity prices are more than twice as high.

${ }^{21}$ For example, the RECS assigns five heating and three cooling degree-day measures to each household, by locating the nearest "representative" NWS station. We use the same eight degree-day series (for all 240 California NWS stations) to determine the household's nearby NWS station. As with the price data, the RECS introduces a small amount of noise into the weather data so that the match is not quite perfect. The primary sources for local utility average electricity and gas prices are FERC Form 1, US Department of Energy Form EIA-861 and Form EIA-412.
} 
With each RECS household matched to its utility and climate zone, the remaining information necessary to determine a household's applicable rate schedule (viz., the household's income and its home heating system) are directly available in the survey. ${ }^{22}$ To complete the procedure, we manually constructed the complete 1993 and 1997 electricity tariff books for each California utility, from filings archived at the California Public Utilities Commission public records library and direct contact with municipal utilities' tariff departments. In the end, the 1,307 California households in the RECS sample were matched to 189 distinct rate schedules.

To provide some information on how well this matching procedure performs, Table 1 lists the major electric service providers in California along with their average residential rate and number of residential customers in 1993. As the survey is a stratified probability sample of California households, we expect (and find) reasonable agreement between what the utilities report as their number of residential accounts and the number of households implied by the survey. ${ }^{23}$ The top and bottom panels of Table 1 divide the state's electric service providers into investor-owned utilities and municipal (or other public) utilities. The table reveals that the implied distribution of RECS households by electric service provider is quite close to that reported separately for the larger utilities. The most notable deviations occur for the two smallest investorowned utilities, Sierra Pacific and PacifiCorp. Both of these utilities serve areas in the mountainous northern and eastern (respectively) areas of the state, have relatively low electricity prices, and minimal natural gas service. We believe that the stratification design and a special segment of the RECS that oversamples low-income households may account for their over-representation. ${ }^{24}$

\subsection{Appliance Demand Specifications}

Our monthly appliance demand specifications are based on prior empirical research that has studied households' appliance use decisions. Principal sources are the EPRI/REEPS model described in LBL (1995) and the EIA Residential End-Use Model, EIA (1995). We model end-use electricity demand using eight distinct appliance categories:

\section{Baseline electricity use;}

\footnotetext{
${ }^{22}$ We also used the RECS' electricity expenditure data to determine which eligible low-income households are actually participating in their utilities' low-income electricity tariff programs.

${ }^{23}$ An unresolved issue is the RECS sampling weights imply 350,000 more California households with electricity service than comparable figures in California utilities' regulatory accounting data. This is evident in the bottom line of Table 1.

${ }^{24}$ The survey's cluster sampling procedure has a countervailing effect, which is to reduce the survey's coverage of smaller utility service areas. We are grateful to U.S. Energy Information Administration analysts for discussions on these RECS sampling design issues.
} 
2. Electric space heating;

3. Central air conditioning;

4. Room air conditioning;

5. Electric water heating;

6. Swimming pools;

7. Additional refrigerators and freezers; and

8. Other appliances.

The baseline category accounts for the electricity consumption of appliances that are universally owned, such as the (first) refrigerator and lights. ${ }^{25}$ This category also implicitly includes consumption attributable to any unspecified electrical appliances below the resolution of the RECS survey (such as electric clocks, irons, hair dryers, and the like). Appliance categories two through six are energy-intensive end uses that previous research indicates exhibit some utilization price elasticity (EPRI (1989)). The final category includes less-energy-intensive household appliances. A description of all appliances entering the model is provided in Table $2 \mathrm{~A}$.

Different factors are assumed to influence appliance-level electricity demand in each category. In particular, we estimate separate price and income effects for each of the first six categories. The remaining appliances are assumed to exhibit a common price effect, as previous studies indicate most of these (refrigeration, cooking, clothes dryers, etcetera) exhibit no significant electricity price elasticity. Demographic and other explanatory variables entering the model are defined in Table 2B. Demographic characteristics of households are assumed constant during the survey year; the monthly-varying covariates in our specifications are the price schedules and the weather data. ${ }^{26}$ All monetary variables are normalized to real (June 1993) prices, using the CPI-U series for California's three consolidated metropolitan statistical areas.

\footnotetext{
${ }^{25}$ Because lights and a (first) refrigerator are owned by all households in our sample, their mean electricity consumption cannot be separately identified by the model.

${ }^{26}$ In addition to the specifications evident in Table 3 below, we imposed a constraint that electricity consumption for space heating and cooling is zero during the summer and winter months, respectively. To accommodate the varied heating and cooling season lengths for different regions and elevations in California, this was implemented via a minimum (one per day) degree-day threshold for the use of these appliances.
} 


\section{Results and Implications}

\subsection{Estimates and Marginal Effects}

The electricity demand coefficients estimated with the generalized method-of-moments technique are shown in Table 3. The table is organized so that each column contains the parameter estimates associated with an appliance category's electricity demand. The mean square error of the estimated model is $2,352 \mathrm{KWh} / \mathrm{year}^{2}$, which is approximately one-third of the sample variance in annual consumption. The chi-square statistic for Hansen's asymptotic test of the over-identifying restrictions is 76.9 ; a value this large is unlikely under the model with simple random sampling (d.f. $=58, p=0.05$ ). ${ }^{27}$

Since the conditional expectation function estimated by the GMM procedure is nonlinear in the parameters, it is difficult to interpret the numerical estimates in Table 3 directly. Table 4 converts these estimates into marginal effects for the principal variables in the model. Table entries show the marginal effect of a one unit increase in each explanatory factor on monthly kilowatt-hour consumption of each specified appliance. We compute marginal effects separately for each household (as the gradient of the conditional expectation function (6) with respect to the explanatory variables), and then average across households using the RECS sampling weights. The marginal effects shown are interpretable as estimated population means for California households, conditional on ownership of the indicated appliance.

The signs and magnitudes of the estimates in Tables 3 and 4 generally agree with prior studies, although there are a few exceptions..$^{28}$ Since our primary interest lies in assessing the effects of price changes on electricity consumption, our comments below focus on the marginal price and income effects and their demand elasticities. Both Tables 3 and 4 indicate that the estimated price effects vary substantially across appliances. The smallest effect is associated with baseline use, and is effectively zero. All other appliance price sensitivities are of considerable practical significance. For example, the -27.5 estimate for price and swimming pools in Table 4 implies that a one cent per KWh increase in the marginal price would reduce a household's annual utilization of pool pumps and motors by approximately $330 \mathrm{KWh}$ per year, which is $15 \%$

\footnotetext{
${ }^{27}$ Since the RECS uses a complex multi-stage sampling design, the true critical values for this statistic are likely to be larger than their standard asymptotic approximations. As actual critical values are difficult to ascertain for this design, we consider a different approach to model validation below in Section 7.4 .

${ }^{28}$ Exceptions are the negative coefficients on income and on the number of rooms in the water heating specification. We suspect this may be due to confounding from unobserved variation in water heater energy efficiency, which is likely to be considerably higher in newer (larger) homes in California. The negative coefficients on the number of household members and space cooling are also of unexpected sign, and may be attributable to an omitted (positive) influence of householder age on space cooling demand.
} 
of a pool's typical electricity use. The price effects for major appliances providing space heating, cooling, and water heating services differ from one another considerably, both in absolute terms and relative to typical consumption for each appliance (see Table 7).

By contrast, the income effects are mostly statistically insignificant and negligible as a practical matter. This is not entirely surprising, given that our analysis is conditional on households' appliance stocks. To the extent that income affects electricity consumption, it is evidently manifest through households' choices of appliances rather than through utilization behavior. These results are consistent with prior studies' findings of low-to-negligible appliance utilization income elasticities at the household level (e.g., Parti and Parti (1980) and Dubin and McFadden (1984)).

The estimated demand model also includes 154 variance and covariance parameters (from equation (10)) that we do not report here. ${ }^{29}$ Our estimates suggest that the variance of household-level unobservable characteristics increases with appliance holdings, although it depends (in a complicated fashion) on the types of appliances owned by the household. For instance, the estimated standard deviation of the stochastic term for baseline electricity consumption (i.e., electricity for the first refrigerator, lights, etc.) is $387 \mathrm{KWh}$ per month ( $\mathrm{SE}=22 \mathrm{KWh} /$ month). If the household's dwelling has electric space heating, the household-level stochastic term has a higher standard deviation of $479 \mathrm{KWh}$ per month ( $\mathrm{SE}=92 \mathrm{KWh} /$ month); if we further add central air conditioning and an electric stove or oven to the household's appliance portfolio, it increases to $590 \mathrm{KWh}$ per month ( $\mathrm{SE}=103 \mathrm{KWh} / \mathrm{month})$. Overall, the standard deviations for the unobservable components of household electricity demand vary widely across households with different appliance portfolios. This reflects-in large part-the enormous differences in maximum potential energy consumption for households with different types of appliances.

\subsection{Price Elasticities}

Table 5 presents estimated average annual household price and income elasticities. These elasticity estimates correspond to the percent change in a household's annual electricity consumption resulting from a one percent increase in the marginal price (or household income) in each month of the year, holding the appliance stock fixed. We calculate demand elasticities separately for each of the 1,307 households in the sample, and then average across households using the RECS sampling weights. The

\footnotetext{
${ }^{29}$ In estimation we use a re-parameterization of the variance function (10) that facilitates estimation but at the cost of increasing the number of parameters. Estimation is easier because the re-parameterized GMM objective function is orthogonal in each of the 154 variance parameters. This re-parameterization imposes positive definiteness but otherwise places no restrictions on the covariance matrix in (10).
} 
elasticity estimates shown in Table 5 are thus interpretable as estimated population means for California households.

Before interpreting these numbers, it is important to note that with non-linear tariffs there is more than one "price" involved in measuring the elasticity of demand. For example, one can calculate the elasticity of demand with respect to an increase in the intercept of the price schedule, with respect to the price of a specific tariff tier, or with respect to the consumer's actual marginal price. We present elasticity estimates based on the third of these interpretations, so as to reflect households' demand sensitivity on the margin. In doing so we recognize the fact that with multi-part tariffs, changing a consumer's marginal price may alter consumption within the current tariff segment or induce a discrete jump to a different price tier. Our elasticity calculations explicitly account for this possibility, using the method described in Appendix A.

We estimate the mean annual electricity price elasticity for California households to be -0.39 . Previous studies of residential electricity demand data have estimated widely varying utilization price elasticities, ranging from nearly zero to about -0.6 . These estimates reflect differences in the geographic regions examined, as well as considerable variation in data types and statistical techniques. Studies conducted by electric utilities, which often have higher-quality data, tend to obtain price elasticities within a narrower range of -0.15 to -0.35 (EPRI (1989)). Our results with the California RECS data fall at this set's upper end, but are close to the -0.35 estimate contained in a much earlier Rand Corporation study of Los Angeles-area households by Acton, Bridger and Howill (1976).

It is interesting to compare our estimates to those obtained for the same households using more traditional estimation methods. If in place of the complete rate schedule we instead use either of the two average price measures available in the RECS, we obtain uniformly smaller (in magnitude) elasticities. Table 5 includes elasticity estimates obtained using OLS with the (statistically exogenous) utility-level average price measure in the RECS; the OLS-based mean household price elasticity is -.28. Similar regressions that incorporate alternative measures of households' rate schedules appearing in the literature (e.g., using the midpoint of the two tiers or the final tier price) also yield smaller price elasticities. These results are consistent with the downward biases one would expect due to the price mis-specification and self-selection problems noted earlier. It also suggests an explanation for why our GMM estimates imply somewhat more price-elastic behavior than many earlier studies' (particularly the utility-conducted studies noted above), in that most of the prior literature handles 
these tariff schedule complexities in either an ad hoc manner or not at all. ${ }^{30}$

\section{Heterogeneity in Price Sensitivity}

While we report single overall price and income elasticities in Table 6, these population means obscure considerable and meaningful heterogeneity in households' price and income elasticities. As noted previously, the model includes separate price and income terms for major appliances. These terms permit households' price and income elasticities to vary across households not just with their consumption level, but also with their appliance holdings. The remaining rows of Table 5 illustrate the marked differences in estimated demand elasticities for households with different heating and cooling systems. Households with electric space heating or air conditioning exhibit a much higher electricity price elasticity than households without such systems. Households that do not use electricity for either of these purposes have an estimated mean price elasticity very close to zero. This heterogeneity is consistent with the limited prior evidence on electricity price elasticity variation across households (e.g., Dubin (1985)). As a practical matter, it suggests that there are effectively two 'types' of households with respect to electricity demand behavior: those who use electricity for space heating or air conditioning and exhibit some electricity price elasticity, and those who do not and are evidently price insensitive.

Further information about the heterogeneity in households' demand elasticities is provided in Figure 2. This figure presents a histogram of the sample households' price elasticities, weighted to estimate the distribution for the California population. Each of the rectangles to the left of the origin represents three percent of California households (e.g., three percent of households have a price elasticity between -0.82 and -0.91). The point-mass at zero indicates that 44 percent of California households exhibit no short-run demand sensitivity to changes in the marginal price of electricity. This segment of the population are households that own no major electric appliances other than a refrigerator, and whose minor appliances fall within the inelastic 'baseline use' category of the model.

Figure 2 brings into focus the substantial heterogeneity in households' price sensitivities. The striking feature of this distribution is its asymmetric, negatively skewed form. This pattern indicates that most households will alter their electricity consump-

\footnotetext{
${ }^{30}$ It is also worth noting that in electricity markets, seemingly small differences in price elasticities are economically quite significant (viz., Table 5's -0.28 using OLS versus -0.39 using complete rate schedules). Assuming a price elasticity that is too small by this difference of -0.1 when increasing rates by (say) three cents per KWh would overestimate annual revenue for California's larger utilities by approximately one hundred million dollars.
} 
tion very little in response to a price change. A small fraction of households, however, are actually elastic demanders (roughly 1 in every 8 families) and would react with large changes in their electricity use. This has noteworthy implications for the welfare effects of electricity price changes, inasmuch as most of the welfare losses from a price increase would evidently be borne by a fairly small share of the consumer population.

Where a household is located in the elasticity distribution is also related to household income and other demographic characteristics. To explore this, Table 6 summarizes household electricity price elasticities by household income and consumption levels. How price elasticities vary with household income (in the cross-section) is of interest because regulatory commissions provide subsidized tariffs to low-income households, and are at times concerned with the consumption incentives of these subsidies. The conventional wisdom is that households with lower incomes are more sensitive to energy prices than households with medium-to-high incomes. The results in the top half of Table 6 are quite consistent with this view, although the magnitudes of the differences across income quartiles are not dramatic.

The lower half of Table 6 indicates how household price elasticities vary with the amount of electricity the household consumes. This relationship is of interest because the aggregate consumption and revenue effects of a tariff change depend upon how elasticities vary across the different tiers of the price schedule. Somewhat surprisingly, we find that elasticities are lower for households that use high amounts of electricity, despite the fact that households with energy-intensive electric space heating/cooling systems have much greater electricity price sensitivity ceteris paribus. This inverse relationship reflects both a weak correlation between household income and ownership of electric space heating/cooling systems, and the fact that households apparently substitute toward more price-inelastic electricity uses as income rises. Thus, from an economic efficiency standpoint, the welfare cost of raising a given amount of revenue will be minimized if the marginal price changes are disproportionately larger for the highest-demand consumers.

\subsection{Appliance Consumption Estimates}

Recall that the estimated model treats total household electricity consumption as the aggregation of individual appliance utilization decisions. A useful feature of this approach is that the fitted model provides estimates of the electricity consumed by each appliance. These appliance-level consumption estimates are of direct interest to energy analysts, and provide a useful benchmark for the model since they can be compared to independent estimates of typical appliance energy consumption.

Table 7 provides the model's predictions about how annual electricity consumption 
varies by appliance. The first numerical column in Table 7 reports the estimated proportion of California households that own particular appliances, based on a weighted average of 1993 and 1997 sample ownership frequencies in the RECS. The second column reports the model's prediction for the average annual electricity consumption of each appliance. These estimates are obtained as the predicted values from the fitted appliance demand equations (7). The appliance consumption estimates are averaged across households (using the RECS sampling weights) so as to reflect typical values in the population of appliance owners.

Comparable appliance-level consumption estimates from prior studies are also listed in Table 7. The third column contains appliance energy consumption predictions from a model developed by the U.S. Energy Information Administration (EIA (1995)). ${ }^{31}$ The final column is from a Lawrence Berkeley Laboratory (LBL (1997)) meta-analysis of numerous residential appliance energy consumption estimates. These estimates are derived from a wide range of direct metering, engineering, and statistical studies of energy use in different areas of the U.S. Overall, there is general agreement between these prior studies and the model's results-perhaps surprisingly so, since the present model is not fit to utilization data for individual appliances. The principal important anomaly occurs with heating, where the LBL survey reports a significantly higher number than we or the EIA do. This can in part be explained by the broader geographic coverage of the LBL analysis and the high sensitivity of heating energy use to climate differences.

\subsection{Household-level Consumption and Sampling Considerations}

In the foregoing discussion, we have interpreted many of the econometric results (for a sample of 1,307 households) as estimates of the corresponding values for a population of approximately 11 million households. This interpretation rests on the fact that the RECS sampling design is intended to produce a representative probability sample of California households. As a caveat to the discussion (and for purposes of interpreting an out-of-sample test, below) it is useful to examine the representativeness of the RECS consumption data and model predictions directly.

Because electric utilities are subject to extensive regulatory reporting requirements, there exist comprehensive aggregate data on utilities' actual sales and number of customers. In principle, averages from these data will differ from their counterparts for the RECS households by amounts attributable to the survey's sampling error. Some

\footnotetext{
${ }^{31}$ This results published by EIA (1995) are based (indirectly) on the same survey data as the present model, so that the EIA (1995) appliance-level consumption figures should not be considered wholly independent estimates.
} 
evidence on this issue is provided in Table 8. The first numerical column in Table 8 presents a weighted average of 1993 and 1997 actual electricity consumption per household for California's four largest utilities and for the state as a whole. ${ }^{32}$ The second column presents the corresponding mean electricity consumption for the RECS sample households along with the standard error of the survey.

Comparing the averages for the state as a whole in the bottom row of Table 8, we see that the RECS understates actual average consumption by slightly more than two standard errors. The 1993 and 1997 RECS samples thus appear to under-represent California household electricity consumption. We also find that the RECS data understate average household consumption for each of the state's four largest utilities, although by sometimes less that two standard errors. ${ }^{33}$ Overall, there is some question as to how representative the RECS is of average household consumption in California.

It is also interesting to compare the model's predictions to the actual and sample consumption averages. Since the model is fit to the RECS data, the difference between the RECS and model averages represents within-sample error. Although the model is nonlinear, the average within-sample error for the full sample is essentially zero. As with the raw sample data, however, the estimated model displays a similar pattern of under-predicting actual consumption for each utility and the state overall. This is not entirely surprising, given that the model can at best capture the behavior of the sample to which it is fit. We conclude that while the RECS sample appears to understate actual household consumption in California, the model does reasonably well (i.e., within a few percent) at fitting the sample data for each utility.

\subsection{An Out-of-Sample Robustness Test}

The validity of the empirical results rest, in part, on the appliance demand specifications and error distribution assumptions of the model. Because we must aggregate over appliances and over time to match the consumption level of the data, these appliance demand specifications are not testable directly. We have already reported the result of a general specification test based on the over-identifying restrictions of the model. A more compelling test, however, is to compare the performance of the model

\footnotetext{
${ }^{32}$ Actual average consumption data were obtained from U.S. Department of Energy Form EIA-861 for calendar years 1993 and 1997. These data include all 46 providers of retail electric service in California.

${ }^{33}$ There are two additional reasons why the utility-specific averages might differ. First, while the RECS is designed to generate a representative sample of households at the state level, the sampling scheme is not designed to produce representative samples within each utility's service territory. Second, the household-utility matching procedure we use to obtain rate schedules (as described in Section 6.1) introduces potential mis-classification error. The difference in state-level average consumption between the RECS and the EIA-861 data is not subject to these caveats.
} 
out-of-sample with actual consumption outcomes made at different prices.

In January 1998, shortly after the end of our sample data, California's three largest investor-owned utilities reduced the price of residential electric service by ten percent. This price change, by virtue of its magnitude and exogeneity to the household, provides a unique opportunity to evaluate the model's out-of-sample accuracy. In addition, 1998 and 1999 were years of the El Niño weather disturbance, which led to substantial changes in California's weather conditions relative to prior years. ${ }^{34}$

Ideally, we would prefer to evaluate the model using within-household differences in predicted and actual consumption between 1997 and 1998 (i.e., a matched-pair test). Unfortunately, due to the triennial (and non-longitudinal) nature of the RECS, we do not have data on actual consumption after 1997 for the sample households. Instead, we can base inference on comparisons to aggregate consumption data reported by California's individual utilities for 1998 and 1999.

To implement a formal test we first extended the weather series used in the model through 1999, for each RECS household. We also collected the exact form of the tariff changes implemented in 1998 and 1999 for each RECS household. ${ }^{35}$ We then use the model to predict what the RECS households would have done in 1998 and 1999, given the price change and weather conditions that actually occurred. We aggregate their responses and, relying on the representativeness of the RECS sample, obtain the model's predictions of what should have happened at the utility level.

Table 9 compares these out-of-sample predictions to actual residential electricity consumption for California's four largest utilities in 1998 and 1999. The second-tolast column provides estimated standard errors for the difference between the actual and predicted consumption averages. These standard errors account for both the nonsampling variance in future consumption outcomes under the model, and the sampling error associated with the RECS multi-stage design. ${ }^{36}$ The final column reports the (two-sided) probability of observing a difference at least as large as that shown, under the maintained assumptions of the model. Small $p$-values constitute evidence against

\footnotetext{
${ }^{34}$ This major weather phenomenon confounds direct causal interpretation of changes in aggregate California electricity consumption between 1997 and 1998-99.

${ }^{35}$ The January 1998 price decrease amounted to lowering each tier of the household's price schedule by ten percent. The actual marginal price change thus depends upon the household's particular rate schedule. There was also a separate price increase for households served by the Los Angeles Department of Water and Power in 1999, which shows up as a notable decline in both actual and predicted consumption for Los Angeles households between 1998 and 1999.

${ }^{36}$ Since we have a nonlinear model and the RECS uses a complex design, the standard errors for this test are inexact. We use a linear approximation (delta) method to estimate the variance of average predicted consumption under simple $(1 / n)$ random sampling, and then inflate the result by the design efficiency ratio of the RECS consumption series (about 1.4) to get the standard errors in Table 9. This method and related techniques are discussed in Skinner, Holt, and Smith (1989).
} 
the validity of the model.

As the findings in Section 7.3 foreshadowed, the model continues to under-predict average consumption in 1998 and 1999. For three of the four utilities in each panel, however, the observed differences from the model's predictions are within the bounds of what may be ascribed to chance by conventional standards of statistical significance. The smallest $p$-values, for Pacific Gas and Electric in 1998 and 1999, are attributable to the particularly acute under-representativeness (relative to sampling error) of the RECS households' consumption data for this utility. Interestingly, for three of the four utilities in each panel, the model's average error (relative to actual) is smaller for the out-of-sample years of 1998 and 1999 than it is for the within-sample years reported in Table 8. On that basis, the model appears to deliver reasonable predictions for how California households' respond to electricity price changes. The under-prediction of consumption remains a concern with these data, however.

\section{Analyzing Tariff Structure Changes}

We now turn from estimation of demand behavior to prediction. One motivation for the model developed in this paper is that it can be used to evaluate, on a prospective basis, the effects of complex rate schedule changes. For a variety of practical reasons, regulatory agencies are often reluctant to authorize randomized-assignment pricing experiments as a means to evaluate major tariff changes. Thus, counter-factual simulations based on econometric models become the analytic method of choice. The accuracy of these simulations is a matter of considerable practical interest, inasmuch as tariff changes for electricity can affect billions of dollars in consumer expenditures.

In this section, we illustrate how the estimated demand model can be used to evaluate the consumption and expenditure effects of a new tariff design. For the sake of concreteness, we consider a specific new system for electricity pricing in California. Following a financial crisis facing that state's utilities in the spring of 2001, the California Public Utilities Commission approved new tariff structures for the state's two largest utilities. The new multi-part tariff structure for residential electric service is shown graphically in Figure 3. Under this five-tier design, the household inherits from its prior (two-tier) tariff a monthly reference quantity, $\bar{x}$. The first $\bar{x}$ kilowatt-hours of monthly electricity consumption are then billed at one price per kilowatt-hour, the next $30 \% \times \bar{x}$ are billed at a higher price, and so forth as indicated in Figure 3 . The reference quantity $\bar{x}$ and the specific tier prices vary based on the utility, the season, the household's climate zone and home heating system, and other factors.

This novel pricing system is intended to achieve several objectives. First and fore- 
most is to raise additional revenue for the state's utilities: As Figure 3 indicates, the household's new price schedule lies everywhere above the prior schedule it replaces. Second, the new tariff is intended to promote energy conservation, particularly among higher-demand consumers. Third, there is a distributive objective underlying this tariff design. Electricity is a necessary good (in the sense that its budget share declines as household income rises), so a uniform increase in price of electricity can be quite regressive. By raising marginal prices more for higher levels of consumption, regulatory authorities hope to attenuate this regressivity and minimize expenditure changes for lower-income households.

Evaluating how well this new tariff system achieves these objectives is a difficult task. Because the five-part tariff is unprecedented in historical consumption data, there is no way to extrapolate its effects using descriptive (i.e., reduced-form) econometric methods. Rather, predicting aggregate demand requires modeling consumer choice behavior under the new tariffs. Such models require household-level data in order to account for consumer heterogeneity and the myriad nonlinear price schedules. Our basic task is to use the disaggregate information on consumers' price sensitivities from the econometric model to predict, household by household, the change in consumption and expenditures under the new price schedule.

There is a complication in carrying out this type of micro-simulation analysis, however. Empirical demand models based on economic theory are formulated assuming the consumer faces a constant marginal price. The econometric model estimated above is no exception to this (see again the discussion following (9)). Some additional effort is therefore required to obtain an econometric model's predictions under alternative supply conditions.

The analysis in Sections 2 and 3 provides one way to do this. To be precise, suppose $j$ indexes the five tiers, $p_{j}$ is the marginal price on tier $j$, and $\bar{x}_{j}$ is the $j$ th-tier upper boundary. For convenience, let $y_{j}$ denote the household's income plus the cumulative rate structure discount applicable in tier $j$, and set $x_{j}=x\left(p_{j}, y_{j}, z ; \beta\right)$. If we let $w$ be the set of observable household characteristics entering the econometric model, then the expected value of monthly household consumption is

$$
\begin{gathered}
E\left(x^{*} \mid w\right)=\sum_{j=1}^{5} P\left(\bar{x}_{j-1}-x_{j}<\varepsilon<\bar{x}_{j}-x_{j}\right) \cdot\left[x_{j}+E\left(\varepsilon \mid \bar{x}_{j-1}-x_{j}<\varepsilon<\bar{x}_{j}-x_{j}\right)\right] \\
+\sum_{j=1}^{4} P\left(\bar{x}_{j}-x_{j}<\varepsilon<\bar{x}_{j}-x_{j+1}\right) \cdot \bar{x}_{j}
\end{gathered}
$$

using the conventions $\bar{x}_{0}=0, \bar{x}_{5}=\infty$. Here $P$ is the distribution of $\varepsilon$ given $w$, and 
all expectations are with respect to this distribution. The first sum on the right-hand side is the contribution to expected consumption conditional on demand crossing the price schedule on one the five steps, and the second sum is the contribution conditional on demand crossing the price schedule in one of the 'gaps' between the steps. As before, this amounts to a probability-weighted average of expected demand within each segment of the new tariff schedule.

Equation (12) is a generalization of the expected two-tier consumption equation (5) derived in Section 3. As in that case, one can interpret (12) in terms of a supply and demand equilibrium at the household level. Specifically, it gives the (expected) solution to intersecting the consumer's demand function (under a constant marginal price) and the new multi-part price schedule in Figure 3. In this way, this prediction equation accounts for the complicated interdependence of the household's marginal tariff segment and the expected consumption level within that segment.

Several other aspects of (12) are worth noting. Its central feature is that it explicitly incorporates the complete structure of the new price schedule. This allows one to address, for example, how consumption or expenditures would differ with a change in specific tier prices or the tariff-step reference quantities. A new tariff structure different from that in Figure 3 would of course require a different prediction equation, but the generalization is by now straightforward.

The probabilistic terms appearing in (12) are present to account for the effect of unobservable sources of variation in households' energy use. These variations must be incorporated explicitly in order to ensure that the new marginal price and consumption level are internally consistent. Stated in behavioral terms, the consumer sorting-onthe-unobservables problem that occurs with multi-part tariffs must be addressed not only in demand estimation but also when predicting consumption at new prices. ${ }^{37}$

Evaluating (12) requires measures of the household's sensitivity to changes in its marginal price, income, and other factors influencing demand. These attributes enter $x_{j}=x\left(p_{j}, y_{j}, z ; \beta\right)$, and affect the tariff tier selection probabilities. This yields an inherently nonlinear relationship between a household's consumption outcome and the household's price elasticity. Such nonlinearities are why the aggregate impacts of a new tariff design depend upon the cross-sectional distribution of consumers' price elasticities.

\footnotetext{
${ }^{37}$ For example, equation (12) differs from what one obtains by simply intersecting the household's estimated demand curve (that is, assuming $\varepsilon$ to be zero) and the new price schedule. That technique implicitly treats the tariff segment selection probabilities in (12) as either zero or one, and ignores the conditional expectation term for $\varepsilon$ on the predicted tariff segment. Unless the variance in the household's future consumption given the observables is in fact zero-in practice an unlikely circumstance-the technique will systematically mis-estimate consumption under a new price schedule.
} 
We use equation (12) and the estimated demand model to evaluate one five-tier tariff system. The specific tariffs considered here were issued in a major regulatory decision by the California Public Utilities Commission in May 2001. They were implemented the following month for approximately 7.8 million households served by the Pacific Gas and Electric Company and the Southern California Edison Company. We should emphasize that California policymakers are pursuing additional initiatives that may affect these households' electricity prices in the future; we do not incorporate adjustments after the May 2001 decision here. ${ }^{38}$

We use publicly available tariff books from the two affected utilities to identify the terms of the new tariff applicable to each household in the RECS sample. ${ }^{39}$ We also make some specific assumptions about the weather, which correspond to evaluating these tariff changes under "normal" California weather conditions. ${ }^{40}$ The tier selection probabilities in (12), which depend upon both the household and its particular tariff schedule, and are evaluated using the normality assumption and household-specific variance estimate from the econometric model. We evaluate the expected consumption equation separately for each of the 1,307 households in the RECS sample, and average these predictions using the survey sampling weights. A similar formula and procedure is used to estimate each household's (expected) expenditures under the new tariff.

Table 10 provides estimates of average household electricity consumption and expenditures under the new five-tier tariffs. For comparison, we also show the values obtained using the prior two-tier tariff schedules in effect from 1998 through 2000. The first numerical column presents estimated population means for all 7.8 million households served by Pacific Gas and Electric and Southern California Edison. The results indicate their average (and aggregate) annual electricity consumption would be approximately 10 percent lower under the new five-tier tariff system than under the preceding tariffs over a normal weather year. The corresponding increase in annual household electricity expenditures is approximately 25 percent, or $\$ 179$ per household (in 1998 dollars). To put this in some perspective, $\$ 179$ is eight percent of the average 1998 state personal income tax liability per household in California.

\footnotetext{
${ }^{38}$ Other ongoing changes to California households' electricity prices include a three-month rebate program for electricity conservation in the summer of 2001, indexed to the household's prior summer energy consumption; the expiration of a 1996 rate discount law that will cause households' electricity prices to rise by approximately $10 \%$ in March 2002; and a regulatory proceeding to revise the tariff-step reference quantities, $\bar{x}$. These actions will produce minor adjustments to the major tariff revision examined here.

${ }^{39}$ Note that approximately ten percent of households participate in a low-income tariff program that is exempt from the new tariff designs. These households appear in our sample, and our predictions for them use their (unchanged) tariffs. The predictions do not account for changes in an eligible non-participating household's incentive to apply for this program, however.

${ }^{40}$ This amounts to using 30-year average heating and cooling degree-days from the NWS station located nearest each RECS household.
} 
It is interesting to note that our expenditure results are considerably lower than the official estimates of the California Public Utilities Commission. That agency predicted the increase in the two affected utilities' total residential electric revenues would be approximately $\$ 1.8$ billion annually, or $\$ 228$ per household. The difference between these two estimates can be explained largely by differences in the assumed demand elasticities. In particular, the Commission uses a so-called 'static scoring' method for predicting the revenue change associated with a new rate schedule design. This amounts to assuming that each consumer's annual demand is completely priceinelastic, so that expenditures changes can be predicted by applying the old and new tariff schedules to the same consumption data. Inasmuch as consumers do exhibit some demand elasticity, this method over-estimates the revenue increase associated with the higher tariff structure.

Since the model we employ is estimated with survey data, we have information on individual households' income levels that can be used to examine the distributional consequences of tariff changes. This issue has not been examined quantitatively in the state regulatory agency's tariff models, as their analyses rely upon utilities' billing data. The additional columns in Table 10 report the model's predictions for average consumption and expenditures by household income quartile. Not surprisingly, under either tariff electricity consumption and electricity expenditures increase with household income. What is interesting to note, however, is that in percentage terms the change in household electricity consumption between the new and old tariff systems is nearly constant across income quartiles. That is, the larger marginal price increases paid by households consuming higher quantities more or less exactly offsets the increasingly inelastic demand behavior of households with higher incomes (see again Table 6).

A similar phenomenon is evident in the estimated expenditures. In absolute terms, however, the increase in expenditures across income quantiles does not rise nearly as fast as income. This implies, and can be verified directly in the unsummarized data, that the new tariff is (slightly) more regressive than the system it replaces. It is, however, considerably less regressive than a revenue-equivalent traditional uniform rate increase, whose distributional impacts California policy makers have sought to avoid.

\section{Conclusion}

The principal motivation for this paper is to better understand the effects of nonlinear tariffs on consumer behavior. This subject has received little attention in the econo- 
metric literature on electricity demand, despite its considerable practical significance. It is our hope (perhaps naively) that this analysis might help practitioners in California and elsewhere begin to resolve some of the uncertainty that pervades complex tariff changes.

More work is of course needed. We should be the first to acknowledge numerous caveats to the foregoing empirical results-including the treatment of short-run versus long-run effects, the evident under-sampling of consumption in the data, and the inherent uncertainty in extrapolating consumption behavior under marginal prices that lie beyond the range of observed experience. All of these concerns suggest a degree of caution is necessary in interpreting our numerical results.

It is worth noting that substantively similar methodological issues arise in a variety of other markets. Regulatory pricing of local telephone service (a perennially controversial matter) and residential water use are leading examples. In those markets nonlinear pricing is quite common, and formal demand analysis is a largely-accepted part of the price-setting process. Some of the econometric issues addressed in this paper would appear germane to those contexts. In a substantively different setting, there are some interesting parallels between the analytical methods examined here and micro-simulation procedures commonly used to evaluate marginal tax rate changes. Specifically, the methodological aspects of implementing 'dynamic' versus 'static' scoring techniques for tax revenues are precisely analogous to the treatment of consumers' demand elasticities in the tariff simulation presented here.

Last, an interesting and useful extension of this research is the normative empirical analysis of nonlinear tariff designs. The methods employed above would appear to lend themselves readily to development of more economically efficient tariffs. For example, if the new five-part tariffs examined above are efficient (in almost any sense of that term), it is surely by fortuity rather than by design. Despite a great deal of work in the theoretical literature on efficient nonlinear pricing schemes, there are as yet few (if any) detailed empirical studies. We leave this subject a matter for future research. 


\section{Appendix A. Elasticity Calculations}

This Appendix describes the method used to calculate the elasticity estimates reported in Tables 5 and 6 . In the present application, calculating elasticities is more complicated than in conventional (uniform pricing) settings. Because of the discrete structure of the price schedule, a change in the consumer's marginal price can move consumption smoothly within a single tariff segment, shift the consumer off or onto the discontinuity between tariff segments, or yield no change in consumption at all. Moreover, the seasonal nature of electricity demand and price schedules imply that a household may face different marginal prices in different times of the year.

We interpret a household's price elasticity of electricity demand to be the (percentage) change in consumption resulting from a (percentage) change in the consumer's marginal price. Since these marginal prices may differ from month to month, the annual elasticity estimates shown in the tables are calculated as the total change in annual consumption associated with an increase in the household's marginal price for each month of the year.

\section{Handling Price Schedule Discontinuities}

From equation (1), we can write the optimal consumption for household $i$ in month $t$ using the equilibrium relation

$$
x_{i t}^{*}=x\left(p_{i t}^{*}, y_{i t}^{*}, z_{i t}, \varepsilon_{i t}\right)
$$

where $y_{i t}^{*}=y_{i t}+\bar{x}_{i t} \cdot\left(p_{i t}^{*}-p_{i t}^{L}\right)$. In this equation, $p_{i t}^{*}$ is the household's marginal willingness to pay for the last unit consumed. This marginal willingness to pay may differ from the marginal price, if consumption occurs at the step-point $\bar{x}$ where the price rises from $p^{L}$ to $p^{H}$. At that point, a small change in either price will have no effect on consumption.

To account for this discontinuous feature of demand behavior in calculating elasticities, we use the following decomposition. Consider an increase in the price of the specific tariff segment in which the household initially consumes. Denoting this initial marginal price as $m p$, and the consumer's initial marginal willingness to pay as $m w t p$, the total change in consumption can be written as

$$
\frac{d x^{*}}{d(m p)}=[\underbrace{\frac{\partial x^{*}}{\partial(m w t p)}}_{\begin{array}{c}
\text { slope of } \\
\text { demand }
\end{array}}+\underbrace{\frac{\partial x^{*}}{\partial y}}_{\begin{array}{c}
\text { marginal } \\
\text { income } \\
\text { effect }
\end{array}} \cdot \underbrace{\frac{d \Delta y}{d(m w t p)}}_{\begin{array}{c}
\text { change in } \\
\text { inframanginal } \\
\text { expenditure }
\end{array}}] \underbrace{\frac{d(m w t p)}{d(m p)}}_{\begin{array}{c}
0 \text { if at } \bar{x}, \\
1 \text { if not }
\end{array}}
$$


where $\Delta y=\bar{x}_{i t} \cdot\left(p_{i t}^{*}-p_{i t}^{L}\right)$ is the rate structure discount (cf. equation (2)). The first term in the square brackets is standard. The remaining terms in the bracketed expression yield the additional income effect due to non-linear pricing (i.e., the effect of changing the rate structure discount). For an optimizing consumer, the last term on the righthand side will be zero if consumption occurs at the step-point, $\bar{x}$, and one otherwise.

For the linear demand specification with the two-tier tariff examined in the paper, this expression takes the simple form:

$$
\frac{d x_{i t}^{*}}{d(m p)}=\alpha \cdot \mathbf{1}\left(x_{i t}^{*} \neq \bar{x}_{i t}\right)+\beta \bar{x}_{i t} \cdot \mathbf{1}\left(x_{i t}^{*}>\bar{x}_{i t}\right)
$$

where $\mathbf{1}(\cdot)$ is the indicator function, and $\alpha, \beta$ are the price and income coefficients from equation (9). We define a household's monthly price elasticity, $\eta_{i t}$, in terms of the effect of price on the margin:

$$
\eta_{i t}=\frac{(m p)_{i t}}{x_{i t}^{*}} \cdot \frac{d x_{i t}^{*}}{d(m p)}
$$

\section{Estimating $\eta_{i t}$}

A wrinkle arises in computing $\eta_{i t}$ : Since our consumption data are aggregated to an annual level, we do not observe the household's monthly consumption, $x_{i t}^{*}$, nor its monthly marginal price. Instead, we estimate $x_{i t}^{*}$ with the 'plug-in' estimator

$$
\hat{x}_{i t}^{*} \equiv E\left[x_{i t}^{*} \mid w_{i t} ; \hat{\theta}\right]
$$

using the conditional moment equation derived in (6) evaluated at the estimated parameter values. We then obtain the marginal price estimate, $\widehat{m p}_{i t}$, from the household's rate schedule in month $t$ for the quantity $\hat{x}_{i t}^{*}$. Finally, we can compute each household's monthly price elasticity using equation (13) as

$$
\hat{\eta}_{i t}=\frac{\widehat{m p}_{i t}}{\hat{x}_{i t}^{*}} \cdot\left[\hat{\alpha}_{i} \cdot \mathbf{1}\left(\hat{x}_{i t}^{*} \neq \bar{x}_{i t}\right)+\hat{\beta}_{i} \bar{x}_{i t} \cdot \mathbf{1}\left(\hat{x}_{i t}^{*}>\bar{x}_{i t}\right)\right]
$$

where the 'hats' indicate estimated quantities.

\section{Annual Elasticities}

To obtain the annual price elasticities reported in Tables 5 and 6, we calculate (pointwise) the percentage change in annual electricity consumption for a percent change in the household's marginal price in each month of the year. That is, for each household 
in the sample we compute

$$
\hat{\eta}_{i}=\frac{1}{x_{i}} \sum_{t=1}^{12} \hat{\eta}_{i t} \cdot \hat{x}_{i t}^{*}
$$

where $x_{i}$ is the household's actual annual electricity consumption. Table 5 reports estimated population means for all California households, obtained by averaging these household-level annual elasticity estimates using the RECS survey weights.

The income elasticities in Table 5 are obtained similarly, after observing that

$$
\frac{d x_{i t}^{*}}{d y}=\beta \cdot \mathbf{1}\left(x_{i t}^{*} \neq \bar{x}_{i t}\right)
$$




\section{References}

[1] Acton, J. P., B. M. Mitchell, and R. S. Mowill (1976). Residential Demand for Electricity in Los Angeles: An Econometric Study of Disaggregated Data. Santa Monica, CA: Rand Corporation, Report R-1899-NSF.

[2] Barnes, R., Gillingham, R. and R. Hagemann (1981). The Short-Run Residential Demand for Electricity. The Review of Economics and Statistics 62: 541-551.

[3] Blomquist, S., and W. Newey (2000). Nonparametric Estimation with Nonlinear Budget Sets. Manuscript, MIT Department of Economics.

[4] Burtless, G. and J. A. Hausman (1978). The Effect of Taxation of Labor Supply: Evaluating the Gary Income Tax Experiment. Journal of Political Economy 86: 1103-1130.

[5] Dubin, J. A. (1985). Consumer Durable Choice and the Demand for Electricity. Amsterdam: North Holland.

[6] Dubin, J. A. and McFadden, D. L. (1984). An Econometric Analysis of Residential Appliance Holdings and Consumption. Econometrica 52: 345-362.

[7] EIA (1994). Sample Design for the Residential Energy Consumption Survey. U.S. Department of Energy, Energy Information Administration, DOE/EIA-0555(94)/1.

[8] EIA (1995). Household Energy Consumption and Expenditures. U.S. Department of Energy, Energy Information Administration, DOE/EIA-0321(93).

[9] EIA (1996). Residential Energy Consumption Survey Quality Profile. U.S. Department of Energy, Energy Information Administration, DOE/EIA-0555(96)/1.

[10] EPRI (1989). Residential End-Use Energy Consumption: A Survey of Conditional Demand Estimates. Palo Alto, CA: Electric Power Research Institute, Report CU-6487.

[11] Fisher, F. M., and C. Kaysen (1962). A Study in Econometrics: Residential Electricity Demand in the United States. Amsterdam: North Holland.

[12] Gabor, A. (1955). A Note on Block Tariffs. Review of Economic Studies 23: 32-41.

[13] Goett, A., and D. McFadden (1985). The Residential End-Use Energy Planning System: Simulation Model Structure and Empirical Analysis. In Advances in the Economics of Energy and Resources, Vol. 5. J. R. Moroney, ed. Greenwich, CT: JAI Press.

[14] Hall, R. E. (1973). Wages, Income, and Hours of Work in the U.S. Labor Force. In Income Maintenance and Labor Supply, Glen G. Cain and Harold W. Watts, eds. New York: Academic Press.

[15] Hanemann, W. M. (1984). Discrete/Continuous Models of Consumer Demand. Econometrica 52: 541-561.

[16] Hausman, J. A. (1985). The Econometrics of Nonlinear Budget Sets. Econometrica 53: 1255-1282.

[17] Heckman, J. (1974). Shadow Prices, Market Wages, and Labor Supply. Econometrica 42: 679-694.

[18] Heckman, J. (1979). Sample Selection Bias as a Specification Error. Econometrica 47: 153-161.

[19] LBL (1995). Residential Sector End-Use Forecasting with EPRI-REEPS 2.1. Berkeley, CA: Lawrence Berkeley Laboratory, Energy Analysis Program. LBL-34044. 
[20] LBL (1997). Energy Data Sourcebook for the U.S. Residential Sector. Berkeley, CA: Lawrence Berkeley Laboratory, Energy Analysis Program. LBL-40297.

[21] Moffitt, R. (1986). The Econometrics of Piecewise-Linear Budget Constraints. Journal of Economics and Business Statistics 4: 317-328.

[22] Nocedal, J., and S. J. Wright (1999). Numerical Optimization. New York: Springer.

[23] Parti, M. and C. Parti (1980). The Total and Appliance-Specific Conditional Demand for Electricity in the Household Sector. Bell Journal of Economics 11: 309-321.

[24] Skinner, C. J., D. Holt, and T. M. F. Smith (1989). Analysis of Complex Surveys. New York: Wiley.

[25] Taylor, Lester D. (1975). The Demand for Electricity: A Survey. Bell Journal of Economics 6: 74-110. 
TABLE 1

Average Price and Number of Households for California Electric Utilities

\begin{tabular}{|c|c|c|c|c|c|}
\hline & \multirow{2}{*}{$\begin{array}{c}\text { Average Residential } \\
\text { Rate in } 1993^{a} \\
\text { (cents per KWh) }\end{array}$} & \multicolumn{2}{|c|}{ Number of Households } & \multicolumn{2}{|c|}{ Percent of Households } \\
\hline & & Actual $^{a}$ & Estimate $^{b}$ & Actual $^{a}$ & Estimate $^{b}$ \\
\hline \multicolumn{6}{|l|}{ Investor-Owned Utilities } \\
\hline Pacific Gas \& Elec. & 12.25 & $3,748,831$ & $4,069,268$ & 34.8 & 36.6 \\
\hline Southern Calif. Edison & 12.10 & $3,636,295$ & $3,655,184$ & 33.8 & 32.9 \\
\hline San Diego Gas \& Elec. & 10.81 & $1,005,257$ & $1,020,010$ & 9.3 & 9.2 \\
\hline PacificCorp (Calif.) & 6.94 & 31,872 & 351,053 & 0.3 & 3.2 \\
\hline Sierra Pacific Pwr. (Calif.) & 8.79 & 36,581 & 169,317 & 0.3 & 1.5 \\
\hline Investor-Owned Subtotal & & $8,458,836$ & $9,264,832$ & 78.5 & 83.3 \\
\hline \multicolumn{6}{|l|}{ Municipal/Public Utilities } \\
\hline Los Angeles & 9.85 & $1,168,229$ & $1,169,431$ & 10.8 & 10.5 \\
\hline Sacramento & 7.65 & 416,364 & 377,054 & 3.9 & 3.4 \\
\hline Riverside & 10.57 & 80,828 & 35,510 & 0.8 & 0.3 \\
\hline Imperial & 8.36 & 67,021 & 7,592 & 0.6 & 0.1 \\
\hline Santa Clara & 7.30 & 38,129 & 126,735 & 0.4 & 1.1 \\
\hline Lompoc & 9.21 & 12,729 & 61,569 & 0.1 & 0.6 \\
\hline Plumas-Sierra & 7.70 & 4,674 & 82,557 & 0.0 & 0.7 \\
\hline Subtotal & & $1,787,974$ & $1,860,448$ & 16.6 & 16.7 \\
\hline \multicolumn{2}{|c|}{ Other Municipal/Public Utilities ${ }^{c}$} & 526,480 & 0 & 4.9 & 0.0 \\
\hline \multicolumn{2}{|l|}{ State Total } & $10,773,290$ & $11,125,280$ & 100.0 & 100.0 \\
\hline
\end{tabular}

${ }^{a}$ Sources: US Dept. of Energy Form EIA-861 (1993), FERC Form 1 (1993).

${ }^{b}$ Estimate based on the 1993 RECS survey data (see text).

${ }^{c}$ Households served by other small municipalities, rural electric cooperatives, and public power districts. 
TABLE $2 \mathrm{~A}$

Appliances Entering Electricity Demand Model

\begin{tabular}{|c|c|c|}
\hline Mnemonic & Appliance & Description \\
\hline & $\begin{array}{l}\text { Primary electric } \\
\text { space heating }\end{array}$ & $\begin{array}{l}1 \text { if household has permanently-installed electric space heating } \\
\text { (electric furnace, heat pump(s), or wall resistance units) }\end{array}$ \\
\hline & Central air cond. & 1 if household has a central air conditioning unit \\
\hline & Room air cond. & 1 if household has room window/wall air conditioning units \\
\hline & Electric water heat & 1 if household has an electric water heater \\
\hline ELECCOOK & Electric cooking & 1 if household has an electric oven and/or stove \\
\hline$E L E C D R Y R$ & Electric dryer & 1 if household has an electric clothes dryer \\
\hline FREEZER1 & Separate freezer & 1 if household has a separate (stand-alone) freezer \\
\hline FREEZER2 & Second freezer & 1 if household has two (stand-alone) freezers \\
\hline FRIDGE2 & Second refrigerator & 1 if household has a second refrigerator \\
\hline CLTHWASH & Clothes washer & 1 if household has an automatic clothes washer \\
\hline$D I S H W A S H$ & Dish washer & 1 if household has an automatic dish washer \\
\hline PORTHEAT & Portable space heat & 1 if household has one or more portable electric space heaters \\
\hline HOTTUB & Hot tub & 1 if household has a hot tub with electric heating \\
\hline POOL & Swimming pool & 1 if household has a swimming pool \\
\hline H2OBEDHT & Waterbed heating & 1 if household has a water bed with electric heating \\
\hline$M I C R O W V$ & Microwave & 1 if household has a microwave oven \\
\hline$N T V$ & Number of TVs & Number of televisions in household \\
\hline
\end{tabular}

TABLE 2B

Additional Explanatory Variables Entering Demand Model

\begin{tabular}{|c|c|c|}
\hline Mnemonic & Variable & Description \\
\hline PRICE & Electricity price & Monthly electricity price, in 1993 cents per kilowatt-hour \\
\hline$I N C O M E$ & Household income & Average monthly household income, in thousand 1993 dollars \\
\hline$H D D$ & Heating degree days & Monthly heating degree days base $60^{\circ} \mathrm{F}$, in hundreds \\
\hline$C D D$ & Cooling degree days & Monthly cooling degree days base $70^{\circ} \mathrm{F}$, in hundreds \\
\hline NROOMS & Number of rooms & Number of rooms in home (excluding bathrooms) \\
\hline NBATHRMS & Number of bathrooms & Number of bathrooms in home \\
\hline NMEMBERS & Number of members & Number of people in household \\
\hline$F R S I Z E$ & Fridge/freezer size & Size of appliance, in cubic feet \\
\hline ATHOME & At home & 1 if someone is normally at home during the day \\
\hline HUPROJ & Housing project & 1 if household resides in a public housing project \\
\hline$A P T B L D G$ & Apartment building & 1 if household resides in an apartment building \\
\hline$R U R A L$ & Rural location & 1 if household resides in a rural location \\
\hline$U R B A N$ & Urban location & 1 if household resides in an urban location \\
\hline YEAR97 & Survey year 1997 & 1 if household data from 1997 survey wave \\
\hline
\end{tabular}


TABLE 3

Electricity Demand Model Coefficient Estimates - GMM Method

(Asymptotic standard errors in parentheses)

\begin{tabular}{|c|c|c|c|c|c|c|c|c|}
\hline $\begin{array}{l}\text { Explanatory } \\
\text { Variable }^{a}\end{array}$ & $\begin{array}{c}\text { Baseline } \\
U_{s e^{b}}\end{array}$ & $\begin{array}{c}\text { Elec. Space } \\
\text { Heating }\end{array}$ & $\begin{array}{c}\text { Central } \\
\text { Air Cond. }\end{array}$ & $\begin{array}{c}\text { Room } \\
\text { Air Cond. }\end{array}$ & $\begin{array}{c}\text { Elec. Water } \\
\text { Heating }\end{array}$ & $\begin{array}{c}\text { Swimming } \\
\text { Pool }\end{array}$ & $\begin{array}{l}\text { Second } \\
\text { Refrig. }\end{array}$ & $\begin{array}{c}\text { Separate } \\
\text { Freezer }\end{array}$ \\
\hline CONST & $\begin{array}{c}-24.6 \\
(49.9)\end{array}$ & $\begin{array}{c}379 . \\
(216 .)\end{array}$ & $\begin{array}{c}312 . \\
(276 .)\end{array}$ & $\begin{array}{l}814 . \\
(369 .)\end{array}$ & $\begin{array}{c}467 . \\
(107 .)\end{array}$ & $\begin{array}{l}514 . \\
(229 .)\end{array}$ & $\begin{array}{c}-23.5 \\
(61.6)\end{array}$ & $\begin{array}{r}-108 . \\
(57.9)\end{array}$ \\
\hline PRICE & $\begin{array}{c}0.4 \\
(3.8)\end{array}$ & $\begin{array}{c}-38.2 \\
(15.0)\end{array}$ & $\begin{array}{c}-23.2 \\
(22.1)\end{array}$ & $\begin{array}{c}-65.3 \\
(32.5)\end{array}$ & $\begin{array}{r}-35.3 \\
(9.6)\end{array}$ & $\begin{array}{c}-28.2 \\
(19.3)\end{array}$ & & \\
\hline$I N C O M E$ & $\begin{array}{c}0.4 \\
(2.4)\end{array}$ & $\begin{array}{c}16.3 \\
(13.1)\end{array}$ & $\begin{array}{c}9.3 \\
(11.0)\end{array}$ & $\begin{array}{c}22.3 \\
(21.5)\end{array}$ & $\begin{array}{r}-34.0 \\
(7.7)\end{array}$ & $\begin{array}{c}6.4 \\
(10.1)\end{array}$ & & \\
\hline NMEMBERS & $\begin{array}{l}18.1 \\
(3.4)\end{array}$ & $\begin{array}{l}-8.0 \\
(20.5)\end{array}$ & $\begin{array}{c}-39.8 \\
(16.8)\end{array}$ & $\begin{array}{c}-53.7 \\
(20.5)\end{array}$ & $\begin{array}{c}49.3 \\
(11.1)\end{array}$ & & & \\
\hline NROOMS & $\begin{array}{l}13.0 \\
(4.5)\end{array}$ & $\begin{array}{c}20.6 \\
(22.3)\end{array}$ & $\begin{array}{c}10.1 \\
(17.9)\end{array}$ & $\begin{array}{c}30.1 \\
(24.1)\end{array}$ & $\begin{array}{c}-36.6 \\
(15.8)\end{array}$ & & & \\
\hline NBATHRMS & $\begin{array}{l}27.3 \\
(9.9)\end{array}$ & & & & $\begin{array}{l}123 . \\
(41.8)\end{array}$ & & & \\
\hline$H D D$ & $\begin{array}{r}-10.7 \\
(6.3)\end{array}$ & $\begin{array}{c}43.8 \\
(22.1)\end{array}$ & & & & & & \\
\hline$C D D$ & $\begin{array}{c}-60.0 \\
(22.7)\end{array}$ & & $\begin{array}{l}240 . \\
(58.8)\end{array}$ & $\begin{array}{r}46.5 \\
(128 .)\end{array}$ & & & & \\
\hline FRSIZE & $\begin{array}{c}6.5 \\
(1.7)\end{array}$ & & & & & & $\begin{array}{c}7.8 \\
(3.7)\end{array}$ & $\begin{array}{c}9.3 \\
(3.3)\end{array}$ \\
\hline DISHWASH & $\begin{array}{c}20.4 \\
(11.5)\end{array}$ & & & & $\begin{array}{c}11.3 \\
(37.3)\end{array}$ & & & \\
\hline CLTHWASH & $\begin{array}{c}18.8 \\
(14.0)\end{array}$ & & & & $\begin{array}{c}71.3 \\
(40.9)\end{array}$ & & & \\
\hline$E L E C D R Y R$ & $\begin{array}{c}66.2 \\
(13.1)\end{array}$ & & & & & & & \\
\hline FREEZER2 & $\begin{array}{l}178 . \\
(55.7)\end{array}$ & & & & & & & \\
\hline
\end{tabular}

Table continues next page 
TABle 3, Continued

\begin{tabular}{|c|c|c|c|c|c|c|c|c|}
\hline $\begin{array}{l}\text { Explanatory } \\
\text { Variable }^{a} \\
\end{array}$ & $\begin{array}{c}\text { Baseline } \\
U_{\text {se }}^{b}\end{array}$ & $\begin{array}{c}\text { Elec. Space } \\
\text { Heating }\end{array}$ & $\begin{array}{c}\text { Central } \\
\text { Air Cond. }\end{array}$ & $\begin{array}{c}\text { Room } \\
\text { Air Cond. }\end{array}$ & $\begin{array}{c}\text { Elec. Water } \\
\text { Heating }\end{array}$ & $\begin{array}{c}\text { Swimming } \\
\text { Pool }\end{array}$ & $\begin{array}{l}\text { Second } \\
\text { Refrig. }\end{array}$ & $\begin{array}{c}\text { Separate } \\
\text { Freezer } \\
\end{array}$ \\
\hline ELECCOOK & $\begin{array}{c}21.5 \\
(11.7)\end{array}$ & & & & & & & \\
\hline MICROWV & $\begin{array}{c}32.8 \\
(12.1)\end{array}$ & & & & & & & \\
\hline HOTTUB & $\begin{array}{l}109 . \\
(32.2)\end{array}$ & & & & & & & \\
\hline PORTHEAT & $\begin{array}{l}108 . \\
(21.1)\end{array}$ & & & & & & & \\
\hline H2OBEDHT & $\begin{array}{c}51.2 \\
(23.7)\end{array}$ & & & & & & & \\
\hline$N T V S$ & $\begin{array}{l}40.7 \\
(5.8)\end{array}$ & & & & & & & \\
\hline ATHOME & $\begin{array}{c}16.0 \\
(10.1)\end{array}$ & & & & & & & \\
\hline$A P T B L D G$ & $\begin{array}{c}-48.8 \\
(14.2)\end{array}$ & & & & & & & \\
\hline HUPROJ & $\begin{array}{c}-79.6 \\
(24.8)\end{array}$ & & & & & & & \\
\hline$R U R A L$ & $\begin{array}{c}31.7 \\
(25.3)\end{array}$ & & & & & & & \\
\hline$U R B A N$ & $\begin{array}{c}-35.8 \\
(12.0)\end{array}$ & & & & & & & \\
\hline YEAR97 & $\begin{array}{c}2.0 \\
(10.3)\end{array}$ & & & & & & & \\
\hline $\begin{array}{l}\text { Model RMSE } \\
\text { (KWh/year) }\end{array}$ & 2352.0 & & & & & & & \\
\hline
\end{tabular}

${ }^{a}$ Estimated on 1307 California households in the 1993 and 1997 Residential Energy Consumption Surveys. The dependent variable is electricity consumption, in KWh; parameter estimates are monthly demand coefficients from equation (7).

${ }^{b}$ This category includes all miscellaneous electrical appliances not explicitly modeled such as lights, household electronics, fans, and so forth. The first refrigerator is included in this category because ownership is nearly universal and its effect not separately identifiable from other universallyowned appliances such as lights. 
TABLE 4

Estimated Marginal Effects

(Asymptotic standard errors in parentheses)

\begin{tabular}{|c|c|c|c|c|c|c|}
\hline \multirow[b]{2}{*}{$\begin{array}{l}\text { Explanatory } \\
\text { Variable }\end{array}$} & \multicolumn{6}{|c|}{ Effect on KWh consumed per month for: ${ }^{a}$} \\
\hline & $\begin{array}{c}\text { Baseline } \\
\text { Use }\end{array}$ & $\begin{array}{c}\text { Elec. Space } \\
\text { Heating } \\
\end{array}$ & $\begin{array}{c}\text { Central } \\
\text { Air Cond. }^{c} \\
\end{array}$ & $\begin{array}{c}\text { Room } \\
\text { Air Cond. }{ }^{c}\end{array}$ & $\begin{array}{l}\text { Elec. Water } \\
\text { Heating } \\
\end{array}$ & $\begin{array}{c}\text { Swimming } \\
\text { Pool }\end{array}$ \\
\hline Price (cents/kwh) & $\begin{array}{c}0.4 \\
(3.7)\end{array}$ & $\begin{array}{c}-37.8 \\
(14.8)\end{array}$ & $\begin{array}{c}-22.5 \\
(21.3)\end{array}$ & $\begin{array}{c}-63.4 \\
(31.1)\end{array}$ & $\begin{array}{r}-34.0 \\
(9.5)\end{array}$ & $\begin{array}{c}-27.5 \\
(18.4)\end{array}$ \\
\hline Income ('000 \$) & $\begin{array}{c}0.4 \\
(2.3)\end{array}$ & $\begin{array}{c}16.2 \\
(13.0)\end{array}$ & $\begin{array}{c}9.1 \\
(10.6)\end{array}$ & $\begin{array}{l}21.6 \\
(20.8)\end{array}$ & $\begin{array}{r}-32.8 \\
(7.5)\end{array}$ & $\begin{array}{c}6.3 \\
(9.8)\end{array}$ \\
\hline N. Members & $\begin{array}{l}18.0 \\
(3.3)\end{array}$ & $\begin{array}{l}-7.9 \\
(20.3)\end{array}$ & $\begin{array}{c}-38.6 \\
(16.3)\end{array}$ & $\begin{array}{c}-52.1 \\
(19.9)\end{array}$ & $\begin{array}{c}47.5 \\
(10.6)\end{array}$ & \\
\hline N. Rooms & $\begin{array}{l}12.9 \\
(4.5)\end{array}$ & $\begin{array}{c}20.4 \\
(22.0)\end{array}$ & $\begin{array}{c}9.8 \\
(17.4)\end{array}$ & $\begin{array}{c}29.2 \\
(23.4)\end{array}$ & $\begin{array}{c}-35.3 \\
(15.2)\end{array}$ & \\
\hline N. Bathrooms & $\begin{array}{l}27.0 \\
(9.8)\end{array}$ & & & & $\begin{array}{l}119 . \\
(40.1)\end{array}$ & \\
\hline $\begin{array}{l}\text { Heating Deg. Days } \\
\left({ }^{\circ} 00^{\circ} \mathrm{F} \text {, base } 60\right)\end{array}$ & $\begin{array}{r}-10.6 \\
(6.3)\end{array}$ & $\begin{array}{c}43.3 \\
(21.9)\end{array}$ & & & & \\
\hline $\begin{array}{l}\text { Cooling Deg. Days } \\
\left({ }^{\circ} 0{ }^{\circ} \mathrm{F} \text {, base } 70\right)\end{array}$ & $\begin{array}{c}-59.5 \\
(22.5)\end{array}$ & & $\begin{array}{l}233 . \\
(57.0)\end{array}$ & $\begin{array}{r}45.1 \\
(123 .)\end{array}$ & & \\
\hline \multicolumn{7}{|l|}{ Dummy Variables } \\
\hline Apt. building & $\begin{array}{c}-48.4 \\
(14.1)\end{array}$ & & & & & \\
\hline Housing project & $\begin{array}{c}-78.9 \\
(24.6)\end{array}$ & & & & & \\
\hline At home during day & $\begin{array}{c}15.8 \\
(10.0)\end{array}$ & & & & & \\
\hline Urban location & $\begin{array}{c}-35.5 \\
(11.9)\end{array}$ & & & & & \\
\hline \multirow[t]{2}{*}{ Rural location } & $\begin{array}{c}31.4 \\
(25.1)\end{array}$ & & & & & \\
\hline & \multicolumn{6}{|c|}{ (Effects of additional appliances are shown in Table 7) } \\
\hline
\end{tabular}

${ }^{a}$ Estimated change in monthly appliance electricity consumption associated with a unit increase in the explanatory variable, ceteris paribus. The marginal effects shown are estimated population means, conditional on appliance ownership.

${ }^{b}$ Heating-season months only.

${ }^{c}$ Cooling-season months only. 
TABLE 5

Price and Income Elasticities For California Households

\begin{tabular}{|c|c|c|c|c|}
\hline \multirow{2}{*}{$\begin{array}{l}\text { Mean Elasticities of } \\
\text { Electricity Demand }^{a}\end{array}$} & \multicolumn{2}{|c|}{ Price } & \multicolumn{2}{|c|}{ Income } \\
\hline & GMM Method & OLS Method & GMM Method & OLS Method \\
\hline All households & -0.39 & -0.28 & -0.00 & -0.00 \\
\hline \multicolumn{5}{|l|}{ Households with: } \\
\hline Electric space heating & -1.02 & -0.85 & +0.00 & +0.01 \\
\hline No electric space heating & -0.20 & -0.11 & -0.00 & -0.01 \\
\hline $\begin{array}{l}\text { Central or room } \\
\text { air conditioning }\end{array}$ & -0.64 & -0.56 & +0.02 & +0.02 \\
\hline No air conditioning & -0.20 & -0.08 & -0.01 & -0.01 \\
\hline $\begin{array}{c}\text { No electric space heating } \\
\text { nor air conditioning }\end{array}$ & -0.08 & +0.03 & -0.01 & -0.02 \\
\hline
\end{tabular}

${ }^{a}$ Annual elasticites (see text and Appendix A). 
TABLE 6

Price Elasticities By

Household Income ANd Electricity Consumption

\begin{tabular}{lccc}
\hline \hline & & & \\
& & & Price Elasticity $^{a}$ \\
\cline { 3 - 3 } Quartile & Quartile Range & GMM Method & OLS Method \\
\hline & & & \\
By household annual income level: & & \\
1st & Less than $\$ 18,000$ & & \\
2nd & $\$ 18,000$ to $\$ 37,000$ & -0.49 & -0.36 \\
3rd & $\$ 37,000$ to $\$ 60,000$ & -0.34 & -0.24 \\
4th & More than $\$ 60,000$ & -0.29 & -0.19 \\
By household & annual electricity consumption: & & \\
1st & Less than $4,450 \mathrm{KWh}$ & -0.46 & -0.31 \\
2nd & 4,450 to $6,580 \mathrm{KWh}$ & -0.35 & -0.28 \\
3rd & 6,580 to $9,700 \mathrm{KWh}$ & -0.32 & -0.26 \\
4th & More than $9,700 \mathrm{KWh}$ & -0.33 & -0.26 \\
& & & \\
\hline
\end{tabular}

${ }^{a}$ Mean annual electricity price elasticity for households within each quartile.

${ }^{b}$ Approximate California household income quartiles, in 1998 dollars. 
TABLE 7

Estimated Electricity Consumption by Household Appliance

\begin{tabular}{|c|c|c|c|c|}
\hline \multirow[b]{3}{*}{ Appliance Type } & \multicolumn{2}{|c|}{ Present Study } & \multicolumn{2}{|c|}{ Prior Estimates $^{a}$} \\
\hline & \multirow{2}{*}{$\begin{array}{c}\text { Households } \\
\text { with appliance, } \\
\text { in percent }^{b}\end{array}$} & \multirow{2}{*}{$\begin{array}{l}\text { Avg. annual } \\
\text { electricity use, } \\
\text { in } \mathrm{KWh}^{b} \\
\end{array}$} & \multicolumn{2}{|c|}{ Average annual use, in KWh: } \\
\hline & & & $\operatorname{EIA}(1995)^{c}$ & LBL $(1997)^{c}$ \\
\hline Elec. space heating & 23.2 & 1,131 & $1,185^{b}$ & $2,609-3,481^{d}$ \\
\hline Central air cond. & 30.3 & 1,270 & $1,283^{b}$ & $1,306-1,446^{d}$ \\
\hline Room air cond. ${ }^{e}$ & 13.7 & 619 & n.a. & $476^{d}$ \\
\hline Elec. water heating & 15.6 & 2,389 & 2,835 & 3,658 \\
\hline Refrigerator & 99.8 & $1,231^{f}$ & 1,141 & 1,144 \\
\hline Electric cooking & 46.0 & 258 & 451 & 822 \\
\hline Separate freezer & 16.7 & 582 & 1,013 & 1,026 \\
\hline Elec. clothes dryer & 32.2 & 795 & 1,090 & 1,000 \\
\hline Clothes washer $^{g}$ & 64.1 & 223 & n.a. & 100 \\
\hline Dishwasher $^{g}$ & 48.3 & 241 & n.a. & 250 \\
\hline Swimming pool & 5.6 & 2,227 & n.a. & $1,500^{h}$ \\
\hline Hot tub & 3.5 & 1,288 & n.a. & 2,300 \\
\hline Water bed heater & 5.1 & 606 & n.a. & 900 \\
\hline Microwave & 83.4 & 388 & n.a. & 132 \\
\hline Televisions $^{e}$ & 98.3 & 482 & n.a. & 513 \\
\hline
\end{tabular}

Notes:

${ }^{a}$ Sources: US Energy Information Adminstration (1995), Table 3.1, and public-use micro files;

Lawrence Berkeley Laboratory (1997), Tables A6 and A7.

${ }^{b}$ Estimates for California households.

${ }^{c}$ Estimates for all U.S. households, except as indicated.

${ }^{d}$ Range of estimates for households in southwestern U.S. states (Calif., Nev., and Ariz.).

${ }^{e}$ Estimates are for all units in household combined.

${ }^{f}$ Estimate based on second refrigerator only.

${ }^{g}$ Excludes energy used to heat water entering washer.

${ }^{h}$ Estimate for pool pump motor only.

n.a. indicates an estimate is not available. 
TABLE 8

Within-Sample Predicted and Actual Consumption

\begin{tabular}{|c|c|c|c|c|c|c|}
\hline \multirow[b]{2}{*}{$\begin{array}{l}\text { Electricity Consumption } \\
\text { per Household, in KWh }\end{array}$} & \multirow[b]{2}{*}{ Actual $^{a}$} & \multicolumn{3}{|c|}{ Sample Data } & \multicolumn{2}{|c|}{ Estimated Model } \\
\hline & & $\begin{array}{l}\text { Sample } \\
\text { Mean }\end{array}$ & $\begin{array}{l}\text { Standard } \\
\text { Error }^{b}\end{array}$ & $\begin{array}{l}\text { Actual } \\
\text { Error }\end{array}$ & $\begin{array}{l}\text { Predicted } \\
\text { Mean }\end{array}$ & $\begin{array}{c}\text { Average Within- } \\
\text { Sample Error }\end{array}$ \\
\hline Pacific Gas \& Elec. & 6,531 & 5,796 & 258 & +735 & 5,899 & +103 \\
\hline Southern Calif. Edison & 6,238 & 6,063 & 291 & +175 & 5,961 & -102 \\
\hline San Diego Gas \& Elec. & 5,706 & 4,627 & 514 & +1079 & 4,775 & +148 \\
\hline Los Angeles Wtr. \& Power & 5,261 & 5,113 & 454 & +148 & 4,867 & -246 \\
\hline All California & 6,355 & 6,007 & 157 & +348 & 6,010 & +3 \\
\hline
\end{tabular}

${ }^{a}$ Weighted average of the total residential sales (in KWh) divided by the number of residential accounts in each of 1993 and 1997, as reported by each utility. Source: US Dept. of Energy Form EIA-861 (1993, 1997).

${ }^{b}$ Standards errors shown account for the multistage sample design of the RECS (see EIA (1994)). 
TABle 9

Out-of-Sample Prediction Tests for 1998 And 1999

\begin{tabular}{|c|c|c|c|c|c|}
\hline $\begin{array}{l}\text { Utility Electricity Sales } \\
\text { per Household, in KWh }\end{array}$ & Actual $^{a}$ & Predicted & Difference & Std. Error & Prob. $^{b}$ \\
\hline \multicolumn{6}{|c|}{ Panel A: 1998} \\
\hline Pacific Gas \& Elec. & 6,775 & 6,198 & +578 & 252 & 0.02 \\
\hline Southern Calif. Edison & 6,455 & 6,233 & +223 & 280 & 0.43 \\
\hline San Diego Gas \& Elec. & 5,935 & 5,005 & +930 & 580 & 0.11 \\
\hline Los Angeles Wtr. \& Power & 5,438 & 4,885 & +554 & 498 & 0.27 \\
\hline \multicolumn{6}{|c|}{ Panel B: 1999} \\
\hline Pacific Gas \& Elec. & 6,905 & 6,187 & +718 & 267 & 0.01 \\
\hline Southern Calif. Edison & 6,423 & 6,257 & +136 & 292 & 0.64 \\
\hline San Diego Gas \& Elec. & 5,964 & 5,078 & +886 & 647 & 0.17 \\
\hline Los Angeles Wtr. \& Power & 4,866 & 4,826 & +40 & 496 & 0.94 \\
\hline
\end{tabular}

${ }^{a}$ Total residential sales (in KWh) divided by the number of residential accounts, as reported by each utility. Source: US Dept. of Energy Form EIA-861 (1998, 1999).

${ }^{b}$ Approximate probability of a difference between actual and predicted at least as large (in magnitude) as observed, under the model. 
TABLE 10

\section{Household Consumption and Expenditure Changes} With Five-Tier TARIFF Schedules

(All monetary amounts in constant 1998 dollars)

\begin{tabular}{cccccc}
\hline \hline & & \multicolumn{4}{c}{${\text { By Income } \text { Quartile }^{b}}^{\text {All }}$} \\
\cline { 3 - 5 } Means per household $^{a}$ & Households & 1st & 2nd & 3rd & 4th \\
\hline & & & & & \\
Consumption (KWh/year) & & & & & \\
With 2 tiers (1998) & 6,196 & 5,524 & 6,299 & 6,330 & 7,455 \\
With 5 tiers & 5,578 & 4,987 & 5,677 & 5,519 & 6,637 \\
Change (\%) & -10.0 & -9.7 & -9.9 & -9.7 & -11.0 \\
Expenditures (\$/year) & & & & & \\
With 2 tiers (1998) & 718 & 633 & 734 & 734 & 873 \\
With 5 tiers & 897 & 770 & 921 & 925 & 1,120 \\
Change (\%) & 24.8 & 21.6 & 25.4 & 25.9 & 28.3 \\
\hline
\end{tabular}

${ }^{a}$ Estimated population means for the 7.8 million California households served by the Pacific Gas and Electric Corporation or the Southern California Edison Company. For calculation methods, see text.

${ }^{b}$ For income quartile breakpoints, see Table 6. 
Figure 1. An Increasing Two-Tier Price Schedule

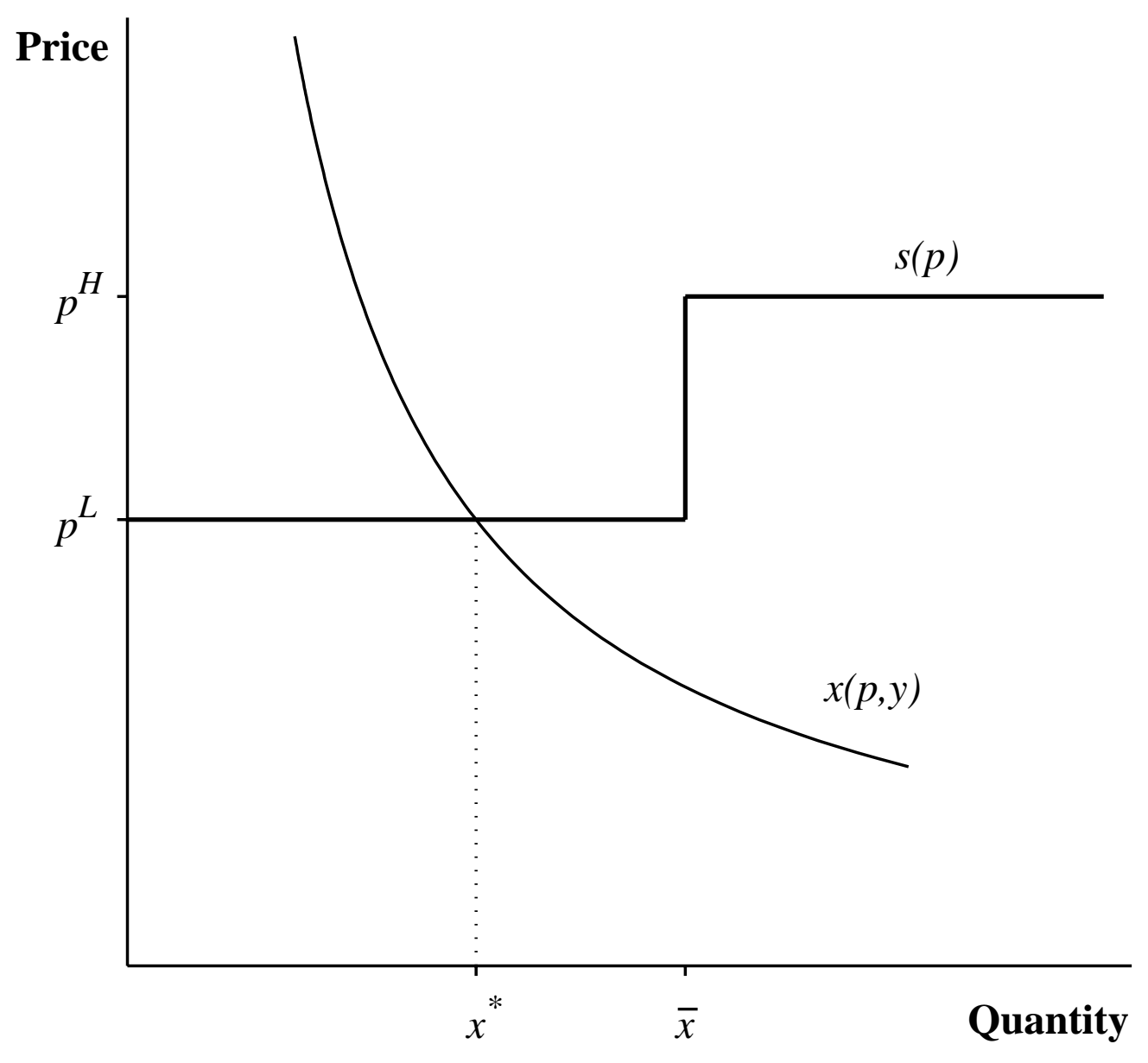


Figure 2. Estimated Distribution of California Households' Electricity Price Elasticities

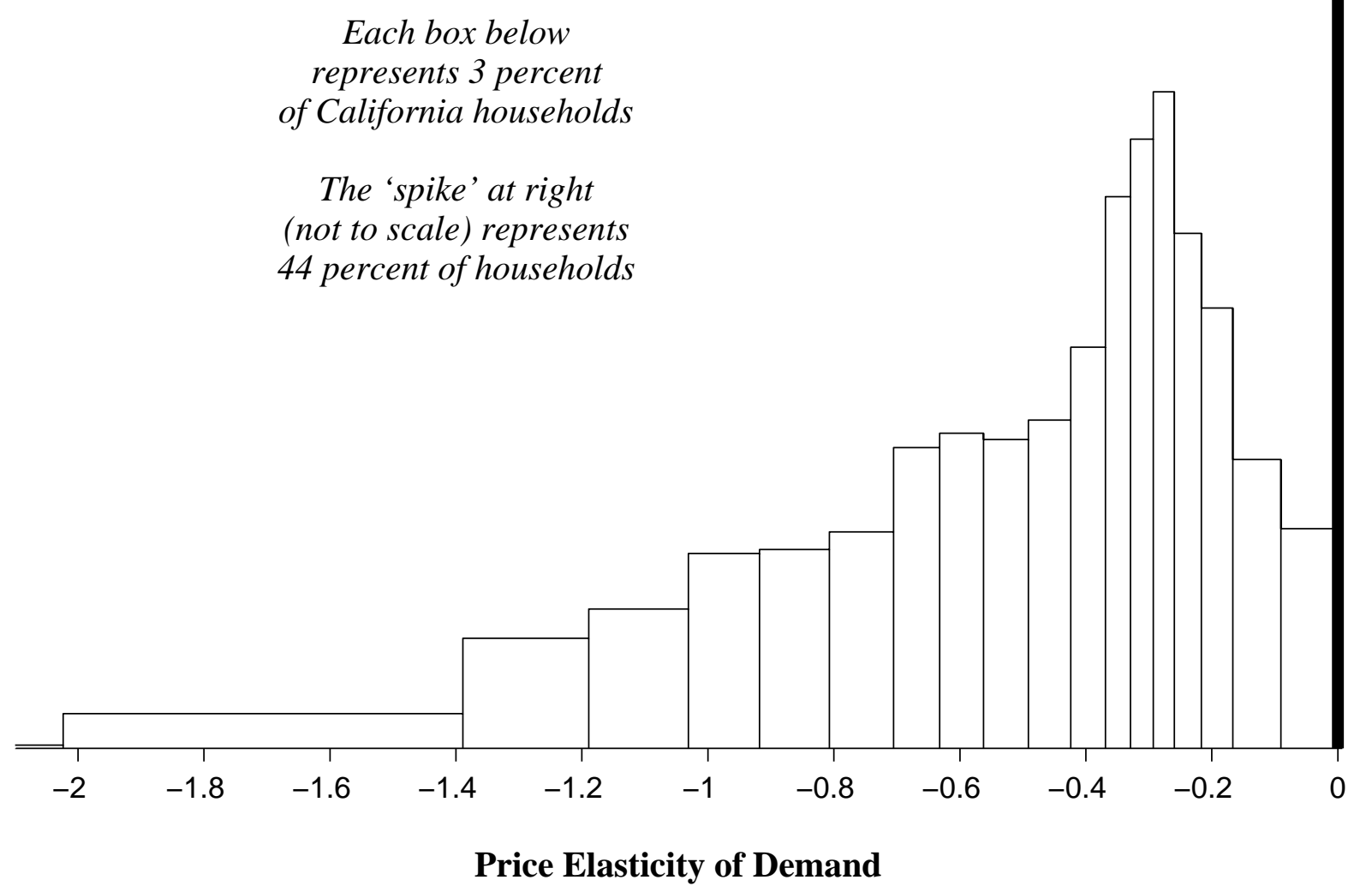




\section{Figure 3. A Five-Tier Electricity Price Schedule}

Illustration for Southern California Edison, Residential Service

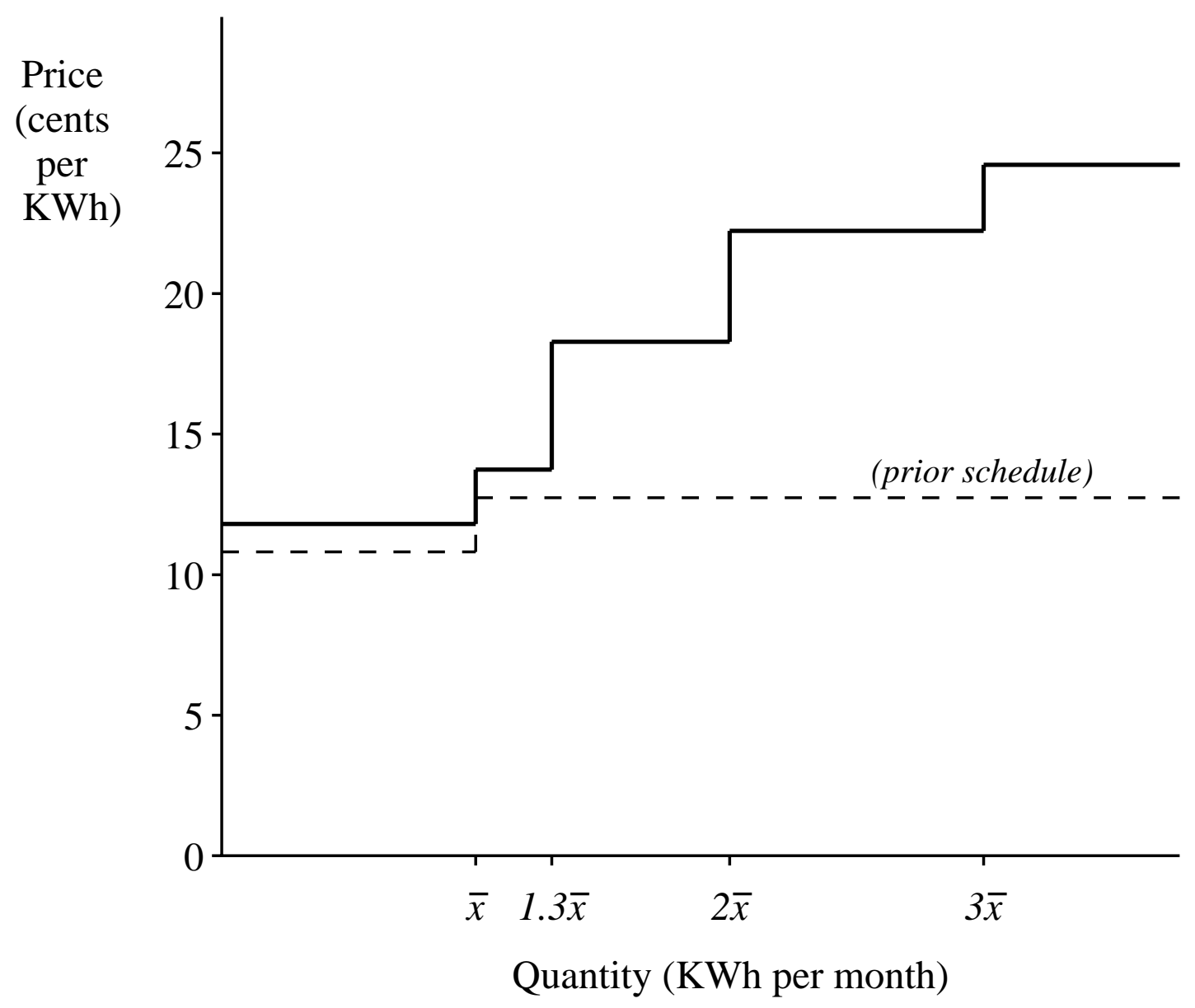

Notes: The "baseline" quantity, $\bar{x}$, varies across households and seasons. The rates depicted above are for the most common residential tariff schedule for this utility. The "prior schedule" shown applied from 1998 through 2000.

Source: Southern California Edison PUC Advice Letter 1545-E, Schedule D, Tariff Sheet 29197-E (2001). 